\title{
CONSUMO de CÁlCIO DIETÉTICO E \\ DENSIDADE MINERAL ÓSSEA \\ EM HOMENS ADULTOS E IDOSOS
}

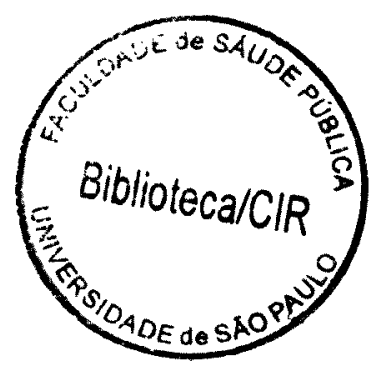

Patricia Constante Jaime

Dissertação de mestrado apresentada à Faculdade de Saúde Pública da Universidade de São Paulo para obtenção do título de Mestre em Saúde Pública.

Área de concentração: Nutrição

ORIENTADORA:

Profa Dra Maria de Fátima Nunes Marucci 


$$
38443199 \text { doe }
$$

Autorizo, exclusivamente para fins acadêmicos e científicos, a reprodução total ou parcial desta dissertação, por processos fotocopiadores.

Assinatura:

Data: 
Aos meus pais:

Darci Constante Jaime e Mauro Gonzaga Jaime, pelo ensino do caminho da perseverança.

Ao meu amor: Manoel Rangel, pelo carinho e companheirismo nesses anos juntos.

À minha vó e minha sogra:

Maria Bela Constante e Geralda Nogueira Rangel, que me despertaram o interesse pelo tema. 


\section{AGRADECIMENTOS}

É grande a lista a quem devo agradecer, porém não é maior que toda minha gratidão:

À minha orientadora Profa Dra Maria de Fátima Nunes Marucci, pelo apoio e confiança em mim depositada.

Ao Conselho Nacional de Pesquisa (CNPq), pela bolsa de estudos concedida.

Ao Dr. Cristiano Augusto de Freitas Zerbini e toda equipe do Serviço de Reumatologia do Hospital Heliópolis, pelo acolhimento que me foi dado.

À Prof. a Dra Maria do Rosário Dias de Oliveira Latorre, do Departamento de Epidemiologia da FSP-USP, pelo grande apoio e valiosos ensinamentos.

À Andréia Elena Moutinho, bolsista $\mathrm{PIBIC/CNPq}$, pela prontidão e responsabilidade. Valiosa foi sua colaboração na realização desse estudo.

Aos colegas e amigos Raquel de Andrade Cardoso, Carla Roberta R. Ferraz, Estefânia Maria Soares Pereira, Maria Teresa Cera Sanches, Teresa Etsuko, Alex Floriano, Tomoe Tanaka, Iracimara Anchieta, Elder Vieira, Lígia Beatriz Bento Franz, Ana Maria Cervato e Fernanda Lopes que de uma forma ou de outra colaboraram para a conclusão desta etapa de minha vida.

Às minhas professoras de graduação, lara Barreto e Maria Margareth Veloso Naves, pelo incentivo inicial, sem o qual talvez eu não tivesse tido coragem para enfrentar o desafio da pós-graduação.

Aos professores e funcionários da FSP-USP, pelos ensinamentos e apoio.

Aos participantes da pesquisa, sem os quais seria impossivel realizá-la.

Aos membros da banca examinadora, pelos aportes a este trabalho.

À minha família, que soube compreender e aceitar o tempo a ela roubado. 


\section{RESUMO}

Jaime PC. Consumo de cálcio dietético e densidade mineral óssea em homens adultos e idosos. São Paulo; 1999. [Dissertação de Mestrado - Faculdade de Saúde Pública da Universidade de São Paulo].

A baixa densidade mineral óssea é um indicador de risco de fratura por osteoporose, importante e crescente problema de saúde pública. 0 consumo deficiente de cálcio acarreta menor mineralização óssea. $O$ presente estudo teve por objetivo identificar as relações entre consumo de cálcio dietético e densidade mineral óssea na coluna lombar, colo do fêmur e conteúdo de cálcio corporal total. É um estudo transversal, abrangendo 296 homens com idade média de 62,5 anos ( $D P=7,9$ ). O consumo de cálcio dietético foi avaliado no momento atual, correspondente ao período de coleta de dados, e ao longo da vida, pelo método de registro alimentar (três dias) e questionário retrospectivo de freqüência de consumo de leite e derivados fontes de cálcio. Para análise da densidade mineral óssea foi realizado o exame de densitometria por emissão dupla de raios $\mathrm{X}$. A análise da densidade mineral óssea foi feita de forma comparativa com os grupos conforme consumo de cálcio dietético, sendo calculado o coeficiente de correlação de Pearson e feitos os testes de diferença de médias, teste $t$-Student e Kruskal-Wallis. 0 consumo de cálcio dietético atual apresentou-se inadequado (72\%) e o pregresso foi considerado adequado $(65 \%)$ para maioria da população estudada. A principal fonte de cálcio dietético consumida no presente foi o leite, seguido dos derivados lácteos. Foram observadas relações entre o conteúdo de cálcio corporal total e o consumo de cálcio dietético tanto no passado como no presente. Contudo, não foi possível observar relações entre o consumo de cálcio dietético atual e pregresso e a densidade mineral óssea na coluna lombar e colo do fêmur, na população estudada de homens com mais de 50 anos.

Descritores: osteoporose, densidade mineral óssea, cálcio, idoso, dieta. 


\section{ABSTRACT}

Jaime PC. Dietetic calcium intake and bone mineral density in adult and elderly men. São Paulo; 1999. [Master thesis dissertation - Faculdade de Saúde Pública, Universidade de São Paulo].

The low bone mineral density is an indicator of osteoporotis fracture risk, an important and increasing health public concern. An insufficient calcium intake results in a lower bone mineralization. The objective of this study was to establish relationship between dietetic calcium intake and bone mineral density at the lumbar portion of the spinal column, femur neck and the total body calcium content. It is a transverse study, including 296 men with age average of 62.5 years (standard deviation $=7.9$ ). The dietetic calcium intake was evaluated both at the current time and throughout their lives. The data was collected using the methods of food intake record (three day) and retrospective questionnaire, regarding the frequency of consumption of milk and dairy products as calcium sources. Measurement of bone mineral density by dual energy $x$-ray absorptiometry. The bone mineral density was analysed by comparing the groups according to their dietetic calcium intake. Pearson's coefficient of correlation was calculated and the average differences were tested using $t$-Student and Kruskal-Wallis methods. The current dietetic calcium intake was inadequate $(72 \%)$, whereas the past intake was considered appropriate $(65 \%)$ for the major part of the studied population. The main calcium source at the current time was milk, followed by dairy products. It was possible to establish relationship between the total body calcium content and dietetic calcium intake in the past and in the current time. However, for the bone mineral density at the lumbar portion of the spinal column and at the femur neck, it was not possible to stablish relationship with current and past dietetic calcium intake in the studied population of men over 50 years old.

Key words: osteoporosis, bone mineral density, calcium, elderly, diet. 


\section{ÍNDICE}

1 - Introdução 1

1.1 - Envelhecimento humano e populacional 2

1.2 - Nutrição e envelhecimento 4

1.3 - Importância do cálcio e seu consumo em nível populacional 7

1.4 - Osteoporose 12

1.5 - Densidade mineral óssea e consumo de cálcio dietético 19

1.6 - Justificativa do estudo 24

2 - Objetivos 25

2.1 - Objetivo geral 26

2.2 - Objetivos específicos 26

3 - Metodologia 27

3.1 - Delineamento do estudo 28

3.2 - População de estudo 28

3.3 - Variáveis de estudo 29

3.3.1 - Densidade mineral óssea 29

3.3 .2 - Consumo de cálcio dietético 30

3.3.2.1 - Consumo de cálcio dietético atual 30

3.3.2.2 - Consumo de cálcio dietético pregresso 34

3.3 .3 - Idade $\quad 34$

3.3 .4 - Outras variáveis $\quad 34$

3.4 - Análise estatística $\quad 35$

3.5 - Programas de computador 36

4 - Resultados 37

5 - Discussão $\quad 49$

6 - Conclusões $\quad 60$

7 - Recomendações $\quad 62$

8 - Referências bibliográficas $\quad 64$

\section{ANEXOS}




\section{INDICE DE TABELAS:}

Tabela 1 - Consumo médio de cálcio ( $\mathrm{mg} / \mathrm{dia}$ ) em populações de 19 países.

Tabela 2 - Distribuição numérica e percentual da população estudada, segundo as características demográficas. Hospital Heliópolis. São Paulo, 1997.

Tabela 3 - Distribuição numérica e percentual da população segundo adequação do consumo de cálcio dietético atual e pregresso. Hospital Heliópolis. São Paulo, 1997.

Tabela 4 - Características da população segundo dados da densitometria óssea. Hospital Heliópolis. São Paulo, 1997.

Tabela 5 - Coeficiente de correlação entre CCD atual e dados da densitometria óssea na população estudada. Hospital Heliópolis. São Paulo, 1997.

Tabela 6 - Diferenças de médias, desvios padrão, valores mínimos e máximos e medianas da densidade mineral óssea, nos três grupos de classificação do CCD atual conforme alcance da recomendação. Hospital Heliópolis. São Paulo, 1997.

Tabela 7 - Diferenças de médias, desvios padrão, valores mínimos e máximos e medianas da densidade mineral óssea, nos dois grupos segundo classificação por adequação do CCD pregresso. Hospital Heliópolis. São Paulo, 1997.

Tabela 8 - Resultados de estudos de consumo de cálcio dietético. 


\section{ÍNDICE DE FIGURAS:}

Figura 1 - Distribuição percentual da população segundo adequação do CCD atual, considerando recomendação do NRC/1989. Hospital Heliópolis. São Paulo, 1997.

Figura 2 - Distribuição percentual da população segundo adequação do CCD no passado. Hospital Heliópolis. São Paulo, 1997.

Figura 3 - Distribuição percentual da população estudada de acordo com a classificação do CCD atual, segundo alcance da recomendação do NRC/1989. Hospital Heliópolis. São Paulo, 1997.

Figura 4 - Distribuição percentual das fontes de cálcio segundo freqüência de consumo. Hospital Heliópolis. São Paulo, 1997.

Figura 5 - Correlação entre DMO na coluna lombar e CCD atual, na população estudada. Hospital Heliópolis. São Paulo, 1997.

Figura 6 - Correlação entre DMO do colo do fêmur e CCD atual, na população estudada. Hospital Heliópolis. São Paulo, 1997.

Figura 7 - Correlação entre conteúdo de cálcio corporal total e CCD atual, na população estudada. Hospital Heliópolis. São Paulo, 1997. 
RELAÇÃO DAS ABREVIATURAS

CCD: consumo de cálcio dietético

DMO: densidade mineral óssea

DP: desvio padrão

FSP: Faculdade de Saúde Pública

IC: intervalo de confiança

NIH: National Institutes of Health

NRC: National Research Council

OMS: Organização Mundial de Saúde

PAM: posto de atendimento médico

USP: Universidade de São Paulo 
1 - INTRODUÇÃO 


\subsection{Envelhecimento humano e populacional}

O envelhecimento humano pode ser conceituado como um processo dinâmico e progressivo onde ocorrem modificaçōes tanto morfológicas como funcionais, bioquímicas e psicológicas. Essas alterações determinam progressiva perda da capacidade de adaptação do indivíduo ao meio ambiente e maior incidência de processos patológicos que terminam por levá-lo à morte (Jacob Filho e Souza 1994).

Envelhecer é uma etapa normal da vida e aqueles que a atingem, entram na chamada "Terceira Idade". De acordo com a Organização Mundial de Saúde (OMS 1974), a Terceira Idade é considerada a partir dos 60 anos de vida nos países em desenvolvimento, e nos países desenvolvidos, a partir de 65 anos. As manifestaçōes do envelhecimento são acentuadas na faixa etária de 60 a 80 anos, porém não há limites bem definidos no tempo (Ferreira 1983).

Entende-se por envelhecimento populacional o aumento da proporção de pessoas com idade avançada em uma população, às custas da diminuição da proporção de jovens nesta mesma população. Segundo a Organizaçăo Mundial de Saúde, uma população envelhecida é aquela em que a proporção de pessoas com 60 anos ou mais, na população total, atinge cerca de $7 \%$, com tendência a crescer (WHO 1983)

Os fatores demográficos mais diretamente responsáveis pelo fenômeno de envelhecimento populacional são a diminuição dos coeficientes de natalidade, de mortalidade, de fecundidade e, por fim, pela elevação das taxas de urbanização. Todos esses fatores exercem efeito decisivo sobre o aumento da expectativa de vida, que está intimamente vinculada à melhoria das condições de vida, de educação e de atenção à saúde. O processo de envelhecimento da população, resultante fundamentalmente da dinâmica dos coeficientes de mortalidade e de natalidade, foi denominado transição demográfica (Berquó e Leite 1988; Camargo e Saad 1990; Veras e col. 1987). 
Esse processo de transição demográfica iniciou-se nos países de capitalismo originário e, posteriormente, passou a ocorrer em todos os países que se transformaram em sociedades urbano-industriais. A partir do fim da Segunda Guerra Mundial, diversos países de capitalismo não desenvolvido também iniciaram seu processo de transição, embora com características e implicações distintas (Patarra 1995).

Nos países desenvolvidos, o processo de transição demográfica teve início nos primórdios do século XVIII, período em que o desenvolvimento social e econômico, decorrente da industrialização, pode garantir conquistas que asseguraram melhores condições de vida à população e uma estrutura de seguridade social relevante. Foi, portanto, um processo determinado predominantemente por fatores sociais e econômicos, ou seja, melhoria de saneamento básico, habitação, condições de trabalho, alimentação e nivel de vida em geral que resultaram na diminuição gradativa das taxas de mortalidade. (Kalache e col. 1987).

Nos países em desenvolvimento como o Brasil, ao contrário, o ritmo da redução da mortalidade foi intenso e ocorreu num período muito mais curto, sendo determinado fundamentalmente por técnicas médicas e sanitárias importadas dos países desenvolvidos, que possibilitaram maior controle das doenças infecciosas (Camargo e Saad 1990).

O Censo Demográfico do Brasil, realizado em 1991, registrou que o brasileiro vive em média 66 anos, porém com diferenças entre as regiões do pais, sendo a região Nordeste a de menor esperança de vida ao nascer. As mulheres vivem mais do que os homens, 69 e 64 anos, respectivamente (Patarra 1995).

Segundo projeções demográficas, o envelhecimento populacional no Brasil se tornará ainda mais acelerado até o primeiro quarto do século 21 , devendo possuir, no ano 2025 , a sexta maior população idosa do mundo, com cerca de 32 milhões de pessoas com idade acima de 60 anos. (Kalache e col. 1987; Schoueri Junior e col. 1994). 
À semelhança do que vem ocorrendo no Brasil, o Estado e o Município de São Paulo vêm apresentando aumento importante da expectativa de vida, para o Estado e Município de São Paulo de 68,2 anos e para a Grande São Paulo de 67,9 anos (Kalache e col. 1987).

Pelo conjunto de observações expostas, não se pode mais conceber o envelhecimento como uma característica própria dos países desenvolvidos, mas, sim, como um fenômeno global e que vem ocorrendo nas últimas décadas com maior intensidade nos paises em desenvolvimento.

Paralelamente às mudanças na estrutura da população, ocorreu a transição epidemiológica, definida como a substituição gradual dos problemas de saúde caracterizados por alta prevalência e mortalidade por doenças infecciosas, para um estado em que passam a predominar as doenças crônicodegenerativas (Laurenti 1990).

As transições demográfica e epidemiológica causam impacto na área da saúde. As doenças infecciosas caracterizadas por curta duração e, em geral, por alta letalidade, são substituídas pelas de longa duração. As doenças crônicas não transmissiveis, em geral, causam incapacidade e dependência, são de longa duração, demandando intervenções mais especializadas e por mais tempo, o que onera muito mais os sistemas de saúde. (Laurenti 1990).

\subsection{Nutrição e envelhecimento}

A Organização Mundial de Saúde, em 1995, implantou um programa sobre envelhecimento e saúde. O propósito deste programa é promover a saúde e o bem estar, aumentando a qualidade de vida por mais tempo para o maior número de indivíduos idosos. Neste sentido, recomenda a realização de estudos sobre nutrição de idosos, assim como a priorização de ações de alimentação e nutrição nos programas com base em comunidades, buscando promover a saúde do idoso (WHO 1995). 
A alimentação é fator primordial para assegurar a saúde das pessoas. $\mathrm{O}$ consumo de alimentos em excesso ou aquém das necessidades, por um longo período, pode constituir fator de risco para doenças ou agravos à saúde que se manifestam comumente a partir da fase adulta e acentuam-se na terceira idade. Por outro lado, uma boa nutrição continuada é um fator determinante da qualidade de vida que uma pessoa pode esperar gozar na velhice (Shuman 1998).

Segundo Mondini e Monteiro (1995), modificações no padrão da dieta do brasileiro, determinadas por alterações na pauta da produção agrícola, pelo desenvolvimento da agroindústria e por mudanças do hábito alimentar geradas com a urbanização, podem ter tido impacto diversificado no perfil de morbimortalidade.

Estudos epidemiológicos têm demonstrado a relação entre tipo de dieta e a incidência de doenças crônicas não transmissiveis, incluindo as doenças cardíacas coronarianas, doenças cérebro-vasculares, neoplasias, diabetes melito, cálculos biliares, cáries dentárias, distúrbios gastrointestinais e várias doenças ósseas e de articulação (WHO 1990).

As mudanças que ocorrem ao longo dos anos têm uma grande influência no estado e necessidades nutricionais. As alterações orgânicas e fisiológicas verificadas no processo de envelhecimento tais como diminuição dos botões gustativos, redução do olfato e da visão, diminuição da secreção salivar e gástrica, falha na mastigação, obstipação, entre outras, afetam diretamente a nutrição do idoso (Curiati e Alencar 1994).

Além dos fatores fisiológicos, outros podem levar a deficiências nutricionais. São fatores decorrentes de mudanças econômicas e no modo de vida que ocorrem com a aposentadoria, isolamento social e solidão, e a incidência aumentada de doenças e incapacidades (Curiati e Alencar 1994; Steen 1990; Veras e col. 1987). 
Os idosos, freqüentemente, apresentam uma série de doenças ao mesmo tempo, e fazem uso de um grande número de medicamentos concomitantemente. Alguns medicamentos podem atuar sobre 0 apetite, paladar e secreção salivar, prejudicando a ingestão de alimentos. A interação droga-nutriente pode ocorrer ao nivel da absorção, metabolismo e excreção de um ou de outro (Marucci e Gomes 1997).

O interesse pela nutrição e saúde de idosos em nível internacional é grande e demonstrado pela realização de vários estudos em diversos locais. Como exemplo, pode-se citar ampla investigação realizada em vários paises da Europa (EURONUT - Seneca), que avaliou o estado de saúde e nutrição de idosos. Essa pesquisa apontou que a alimentação da população idosa da maioria dos centros estudados não atendia às recomendações nutricionais para vitaminas e minerais (Cruz e col. 1991). Ainda na Europa, Elsborg, em 1983, analisando a dieta de idosos italianos não institucionalizados, concluiu que nenhuma atendia às recomendações em relação às vitaminas e minerais analisados (folato, vitamina $D$, vitamina $C$, vitamina $B_{2}$, vitamina $A$, vitamina $B_{12}$, zinco, ferro e cálcio).

No Brasil, apesar de escassas, as pesquisas sobre a alimentação de idosos têm sido feitas, buscando identificar a adequação da dieta, bem como os hábitos alimentares. Esses trabalhos têm verificado, assim como os estudos de outros países, inadequação da dieta de idosos, inclusive no que se refere a micronutrientes (Marucci 1985, 1992; Najas e col. 1994; Frank 1996; Sampaio 1997).

Dentre os nutrientes apontados como deficientes na dieta dos idosos, tanto em estudos internacionais como nacionais, o cálcio é um dos mais citados. 


\section{3) Importância do cálcio e seu consumo em nível} populacional:

O cálcio é um mineral essencial na alimentação do homem, uma vez que seu corpo necessita desse nutriente, ao longo da vida, para o desenvolvimento e manutenção do esqueleto ósseo, e o organismo não é capaz de sintetizá-lo (Czajka-Narins 1998). Caracteriza-se por ser o mineral mais abundante, representando por volta de $2 \%$ do peso corporal e $39 \%$ dos minerais totais presentes no corpo humano. $O$ conteúdo de cálcio no esqueleto corresponde a $25 \%$ do seu peso seco. A concentração de cálcio nos fluidos extracelulares é de 6 a $7 \mathrm{mg} / 100 \mathrm{ml}$ (Nordin 1997a).

O corpo adulto tem cerca de $1200 \mathrm{~g}$ de cálcio, estando $99 \%$ deste presente nos tecidos duros, como ossos e dentes, e $\circ 1 \%$ restante no sangue, fluidos extracelulares, estruturas intracelulares e nas membranas das células. Este cálcio extra-esqueleto desempenha importante função na condução nervosa, na contração muscular, na coagulação sangüínea e na permeabilidade de membranas (NRC 1989; Heaney 1997).

O cálcio confere rigidez ao esqueleto pela sua capacidade de formar sais insolúveis com o ácido fosfórico. Esses sais de cálcio constituem, ainda, grande reserva para manutenção da concentração normal de cálcio no líquido extra-celular (Nordin 1997a).

As principais fontes alimentares de cálcio são os leites e os seus produtos derivados como: queijo, iogurte, coalhada, requeijão; exceto manteiga e creme de leite. (IBGE 1977; Franco 1992; Philippi e col. 1996; Pinheiro e col. 1996). O consumo adequado de cálcio pode ser alcançado através da dieta, dos alimentos fortificados com cálcio, dos suplementos de cálcio ou pela combinação destes (NIH 1994). Contudo, o cálcio contido no alimento é melhor absorvido do que aquele consumido isoladamente nos suplementos e evita o desequilíbrio de minerais, uma vez que, com o alimento, outros nutrientes são oferecidos além do cálcio (Heaney e col. 1990; Weaver 1992; Fujita 1997). 
A recomendação de cálcio, para indivíduos americanos com 51 anos e mais, é de $800 \mathrm{mg} / \mathrm{dia}$ (Recommended Dietary Allowances - RDA-NRC, 1989). Apesar da importância do cálcio na nutrição, ainda não existe para a população brasileira uma recomendação específica para o consumo deste nutriente, sendo então utilizada a do National Research Council (NRC 1989).

O consumo médio de cálcio é largamente diversificado em todo o mundo, conforme demonstrado na tabela 1 . As diferenças são marcadamente determinadas pela variação no consumo de produtos lácteos, que se caracterizam como as principais fontes alimentares de cálcio (FAO 1991 citado por Nordin 1997a).

Tabela 1: Consumo médio de cálcio (mg/dia) em populações de 19 países.

\begin{tabular}{l|c}
\hline \multicolumn{1}{c|}{ País } & Consumo de cálcio (mg/dia) \\
\hline Guatemala & 262 \\
Jamaica & 319 \\
Japão & 354 \\
Brasil & 406 \\
Chile & 466 \\
Colômbia & 519 \\
Equador & 529 \\
Argentina & 603 \\
Itália & 637 \\
Israel & 704 \\
Nova Zelândia & 771 \\
Reino Unido & 855 \\
Canadá & 898 \\
Austrália & 921 \\
França & 969 \\
Dinamarca & 974 \\
Holanda & 997 \\
Noruega & 1002 \\
Finlândia & 1267 \\
\hline
\end{tabular}

Fonte: adaptado de FAO 1991.

Especificamente sobre o consumo de cálcio dietético em adultos e idosos, várias pesquisas têm demonstrado um consumo abaixo de $800 \mathrm{mg}$ (RDA - NRC 1989).

Revisão sobre a alimentação de idosos, desenvolvida por O'Hanlon e Kohes (1978), avaliou, comparativamente, os resultados de pesquisas 
realizadas com idosos norte-americanos, utilizando diferentes métodos de inquérito alimentar. Os resultados obtidos mostraram que o cálcio foi o nutriente que mais freqüentemente encontrava-se abaixo da recomendação, independentemente da metodologia utilizada para avaliar o seu consumo.

Fleming e Heimbach (1994), avaliando o consumo de cálcio da população dos EUA, identificaram consumo médio de $736 \mathrm{mg}$ que variou por região, renda (gastos com moradia), grupo étnico, sexo e idade. Para a mulheres entre 60-69 anos, o consumo médio foi de $579 \mathrm{mg}$, e aquelas com 70 anos e mais apresentaram um consumo médio de $589 \mathrm{mg}$, ou seja, abaixo da recomendação de $800 \mathrm{mg} / \mathrm{dia}$ (NRC 1989). Os homens idosos também apresentaram consumo de cálcio abaixo da recomendação, contudo com média acima das mulheres idosas em aproximadamente $150 \mathrm{mg}$. Observou-se, em todos as categorias de renda, inadequação no consumo de cálcio, sendo que a categoria de menor renda apresentou consumo médio de $673 \mathrm{mg}$ e a de maior renda de $784 \mathrm{mg}$, com diferença aproximada de $15 \%$.

Sloutskis e col. (1995), através de dados de estudo populacional na Suiça, com indivíduos de 35 a 65 anos, concluiram que cerca de $60 \%$ dos homens e $80 \%$ das mulheres não consumiam diariamente a quantidade recomendada de cálcio para prevenção de osteoporose, que seria de 800-1000 $\mathrm{mg}$ de cálcio/dia na idade adulta e $1400 \mathrm{mg}$ para mulheres na menopausa. $\mathrm{O}$ consumo médio de cálcio para homens foi $656 \mathrm{mg}$ e para mulheres $489 \mathrm{mg}$.

Chapman e col. (1995), avaliando o consumo de cálcio em mulheres de 22 a 85 anos, no Estado de Illinois - EUA, verificaram consumo médio diário de $591 \mathrm{mg}$, sem diferenças entre indivíduos com idade inferior ou superior a 50 anos. Constants e col. (1994), por sua vez, avaliando o consumo de cálcio em idosos franceses, verificaram que, antes de uma intervenção nutricional, o consumo médio era menor do que $800 \mathrm{mg} / \mathrm{dia}$, o qual aumentou após a intervenção. A deficiência tendeu a ser mais freqüente nas mulheres do que nos homens. 
Looker e col. (1993), em estudo comparativo sobre o consumo de cálcio em pessoas de diferentes origens (mexicana, cubana, porto-riquenha, branca e negra não-hispânicas), residentes nos EUA, identificaram nas mulheres de todas as origens e grupos étnicos, consumo médio abaixo da recomendação para cálcio, aproximadamente $70 \%$ da recomendação. Contudo, para as negras não-hispânicas, o consumo atingiu apenas $50 \%$ da recomendação (NRC 1989).

No Brasil, existem alguns trabalhos sobre o consumo de cálcio por idosos como o de Marucci (1985), que avaliou a dieta oferecida em 20 instituiçōes para idosos, localizadas no município de São Paulo e constatou inadequação de cálcio em $\mathbf{9 0 \%}$ das instituições estudadas. Também Sampaio (1997), em estudo desenvolvido nesse mesmo município, porém com idosos da comunidade, verificou que a maior parte da população estudada consumia dietas insuficientes em cálcio. Frank (1996), em estudo antropométrico e dietético de idosos no Estado do Rio de Janeiro, constatou que $43,3 \%$ dos idosos do sexo masculino apresentaram ingestão de cálcio abaixo de 800 $\mathrm{mg} / \mathrm{dia}$, enquanto que no sexo feminino essa proporção alcançou $59 \%$.

Apesar da observação da inadequação da dieta de idosos em relação ao cálcio, tanto em estudos internacionais como nacionais, os fatores que podem influenciar negativa ou positivamente no consumo não estão bem definidos. Ainda são poucos os dados publicados sobre atitudes e práticas relativas ao consumo de cálcio dietético.

Horwath e col. (1995) pesquisaram os fatores que influenciavam o consumo de leite e produtos lácteos em mulheres jovens e idosas, na Nova Zelândia. Entre as mulheres jovens, a relação estabelecida entre aumento do peso corporal e maior consumo desses alimentos, foi considerado um fator negativo que influenciou no consumo do cálcio. Cerca de 13 a $18 \%$ das mulheres entrevistadas receberam aconselhamento médico para eliminar leite e produtos lácteos de suas dietas. Nos dois grupos, a aversão foi o fator mais citado para não consumir uma maior quantidade de leite. Uma suposta 
preocupação com a saúde foi a principal responsável pelo não consumo de produtos lácteos em maior quantidade.

Segundo Upritchard e Ball (1996), dietas com baixo teor de gordura têm sido largamente recomendadas para o tratamento de indivíduos com hiperlipidemia e obesidade, integrando a terapêutica para redução dos riscos de doenças coronarianas. Contudo, os autores sugerem que estas dietas mal orientadas podem não prover a quantidade recomendada de cálcio, e, também, que o controle da ingestão calórica e lipídica não requer, necessariamente, a exclusão de leite e produtos lácteos da dieta, uma vez que estes alimentos também estão disponiveis na forma de desnatados e semi-desnatados, mantendo ou mesmo aumentando seu conteúdo em cálcio, preservando assim seus benefícios para a saúde corporal.

Walker e Ball (1993) investigaram o consumo de cálcio em mulheres entre 40 e 65 anos que consumiam dieta hipolipídica e apresentavam inadequação na ingestão de cálcio. Essa mulheres foram orientadas sobre a importância do cálcio e os meios de aumentar sua ingestão, e observou-se, três meses após a orientação nutricional, que o consumo de cálcio aumentou significantemente, atingindo a recomendação, sem contudo ter havido aumento do consumo energético e de gordura saturada.

Chapman e col. (1995) avaliaram a associação entre vários fatores, que poderiam influenciar o consumo de cálcio e produtos lácteos, com dados dietéticos de mulheres com idade entre 22 e 85 anos, e constataram que a osteoporose foi associada ao baixo consumo de cálcio em $97 \%$ das entrevistadas.

Outros estudos têm associado o baixo consumo de cálcio à osteoporose, hipertensão arterial e alguns tipos de câncer, como de cólon e mama (Heaney e col. 1982; Witteman 1989; Garland e col. 1991; Heaney 1991; McCarron e col. 1991, McCarron 1995; Cappuccio e col. 1995; Knekt e col. 1996). 
O consumo inadequado de cálcio e suas implicações nos processos fisiológicos e patológicos são de interesse crescente e o aumento do número de publicações reflete a preocupação sobre o tema.

\section{4) Osteoporose:}

"A osteoporose é uma doença que se caracteriza por baixa massa óssea, deterioração da microarquitetura do tecido ósseo, levando a um aumento da fragilidade óssea, e a um conseqüente aumento no risco de fratura". (Consensus Development Conference: osteoporosis 1993).

As manifestações clínicas da osteoporose são as fraturas ósseas de fragilidade, que são reconhecidas como um importante e crescente problema de saúde pública no mundo. Esta condição de redução do tecido mineral ósseo é responsável por um aumento da mortalidade e morbidade, e perda de habilidades funcionais devido a fraturas de vértebras, da porção proximal do fêmur, porção distal do rádio e quadril (Arnauld e Sanchez 1990; Kanis e Pitt 1992; Constants e col. 1994; Cooper 1996; Gullberg e col. 1997).

A mais grave fratura osteoporótica é a de quadril, que causa intensa dor e, na maioria das vezes, necessita de hospitalização. A sua incidência aumenta exponencialmente com o aumento da idade, tanto no sexo masculino como no feminino. As fraturas de quadril são as principais contribuintes para a mortalidade e morbidade por fraturas. Várias pesquisas indicam que entre $12 \mathrm{e}$ $40 \%$ dos pacientes que têm este tipo de fratura morrem em 6 meses, e que a taxa de mortalidade encontrada é de 12 a $20 \%$ maior do que em população de mesma idade e sexo sem fraturas. Também ocorre importante queda da capacidade funcional e da habilidade para desenvolver atividades da vida diária. Estas últimas conseqüências contribuem para, aproximadamente, 30\% de institucionalização daqueles pacientes que tiveram fratura de quadril. (Cummings e col. 1985; Kanis e Pitt 1992; Cooper 1996). 
A importância da fratura de quadril tem sido relatada em alguns paises. A magnitude do problema destas fraturas é considerável. Estimativas de risco para as populações da Europa e Estados Unidos da América (EUA), variam de 10 a $15 \%$ em mulheres com 50 anos e um terço ou metade deste valor para homens (Cummings e col. 1985; Johnell e col. 1992; Elffors e col. 1994). O risco de fratura de quadril durante toda a vida é estimado em $17 \%$ para mulheres brancas, $6 \%$ para homens brancos, $5,6 \%$ para mulheres negras e $2,8 \%$ para homens negros (Melton e col. 1988; Cummings e col. 1989).

Gullberg e col. (1997) fizeram uma projeção mundial de fraturas de quadril. Considerando as estimativas de envelhecimento populacional e assumindo que nenhuma mudança ocorrerá na incidência específica por sexo e idade, o número de fraturas foi estimado em aproximadamente 2,6 milhões em 2025 e 4,5 milhões em 2050. Os autores discutem que o percentual de aumento das fraturas de quadril possivelmente será maior nos homens $(310 \%)$ do que nas mulheres $(240 \%)$, decorrente do aumento da expectativa de vida no sexo masculino. $O$ crescimento do número de fraturas será maior nos países que apresentam mudanças demográficas com envelhecimento populacional intenso, como é o caso dos paises da Ásia, América Latina, Oriente Médio e África. Desta forma, o impacto sócio-econômico das fraturas de quadril poderá aumentar marcadamente no mundo, e, em especial, nos países de economia pouco estável.

Várias pesquisas têm apontado para uma progressão da incidência e prevalência de fraturas por osteoporose, ou seja, tem havido um aumento no risco de fratura específico para sexo e idade, de modo similar em homens e mulheres (Melton e col. 1987; Kanis e Pitt 1992; Gullberg e col. 1997). Caso esta situação se mantenha, o número de fraturas de quadril em 2025 e 2050, poderá ser maior do que os valores projetados por Gullberg e col. (1997), como os próprios autores discutem em seu trabalho.

São poucos os estudos que abordam a incidência de fraturas de quadril na América do Sul. Pelos dados disponiveis, a incidência neste continente parece ser menor do que a estimada para várias populações da 
Europa e dos EUA. A epidemiologia da osteoporose na América do Sul é ainda incompleta, com estudos realizados apenas em alguns países e dados, em sua maioria, não representativos em termos populacionais. É importante lembrar que a América do Sul é um continente bastante extenso e heterogêneo nos aspectos geográficos, socio-econômicos, culturais, históricos e étnicos, o que pode contribuir para uma variação na forma de apresentação da osteoporose entre um país e outro.( Spindler e col. 1995; Szejnfeld e col. 1995; Mautalen e Pumarino 1997).

Apesar de a magnitude do problema das fraturas por fragilidade na América do Sul ser menor do que em outros continentes, a osteoporose também é considerada um problema de saúde pública e poderá se ampliar com o envelhecimento populacional, como exposto por Gullberg e col. (1997).

O custo das fraturas por osteoporose é alto. Em 1995, foram gastos, nos EUA, 13,8 bilhões de dólares com o tratamento dessas fraturas (Ray e col. 1995). Estratégias de prevenção das fraturas e conseqüente economia no seu tratamento, obrigatoriamente passam pela redução na incidência de osteoporose.

Estudo recente, realizado nos EUA, estimou que cerca de 13 a $18 \%$ de mulheres com mais de 50 anos têm osteoporose e $37 \%$ têm osteopenia; e nos homens de 3 a $6 \%$ na mesma faixa etária têm osteoporose e de 28 a $47 \%$ têm osteopenia (Looker e col. 1997). Nos EUA e na Europa, a osteoporose causa aproximadamente 2,3 milhões de fraturas por ano (Consensus Development Statement 1997).

A prevenção da ocorrência de fraturas por osteoporose depende da identificação dos indivíduos com maior propensão a estas fraturas de tal forma que uma intervenção em saúde possa ser realizada. Embora fatores de risco possam ser identificados, a medida da massa óssea ainda é o fator preditivo mais importante na abordagem do risco de fratura. A densitometria por raios $X$ de dupla energia (DEXA) tem sido a técnica mais largamente utilizada em todo o mundo, para avaliação da massa óssea (Zerbini 1998). 
Vários autores têm indicado que o risco de fraturas de fragilidade aumenta progressivamente com a diminuição da densidade mineral óssea, enfatizando assim a utilização da medida da massa óssea como preditor do risco futuro de fratura (Consensus Development Conference 1993; Kanis e col. 1994; Zerbini 1998).

Os conceitos de osteoporose e osteopenia são baseados na comparação da medida da densidade óssea de um indivíduo com a densidade da média do pico de massa óssea de adultos jovens saudáveis. Um limiar de massa óssea utilizado para a definição de osteoporose em indivíduos sem fraturas tem sido aceito pela Organização Mundial de Saúde. (WHO 1994; Kanis e col. 1994).

Este critério diagnóstico é estabelecido para mulheres adultas, como:

Normal: um valor da densidade mineral óssea ou do conteúdo mineral ósseo inferior a 1 desvio padrão (DP) abaixo do valor médio do adulto jovem.

Osteopenia: um valor da densidade mineral óssea ou do conteúdo mineral ósseo entre 1 e 2,5 DP abaixo do valor médio do adulto jovem.

Osteoporose: um valor da densidade mineral óssea ou do conteúdo mineral ósseo superior a 2,5 DP abaixo do valor médio do adulto jovem.

Osteoporose severa (ou osteoporose estabelecida): um valor da densidade mineral óssea ou do conteúdo mineral ósseo superior a 2,5 DP abaixo do valor médio do adulto jovem, na presença de uma ou mais fraturas de fragilidade.

O estabelecimento dos diagnósticos de osteoporose e osteopenia baseado na comparação da densidade mineral óssea (DMO) de indivíduos jovens normais é clinicamente adequado porque a força do osso é determinada pelo seu conteúdo absoluto de mineral, independentemente da idade em que é medido (Ott 1993).

Existem algumas limitações na utilização deste critério diagnóstico para osteoporose, decorrente dos valores referenciais da média de densidade mineral óssea do adulto jovem. Esses valores foram descritos a partir de dados populacionais de mulheres brancas e a sua utilização em homens e/ou em mulheres de outras etnias pode não ser apropriada (Kanis e col. 1994). 
Desta forma, para que seja possivel a categorização da quantidade de massa óssea em homens e mulheres de outras etnias, estudos prospectivos precisam ser realizados para identificar o risco absoluto de fratura nesses grupos para diferentes níveis de densidade mineral óssea.

Em recente estudo sobre a prevalência de baixa densidade mineral óssea na população dos EUA, estabeleceram-se médias de pico de massa óssea ajustadas por etnias e sexo. Observou-se que, para os homens, as estimativas variaram de acordo com o gênero do grupo de referência utilizado para estabelecer os pontos de corte ( valores médios da densidade mineral óssea obtidos no pico de massa óssea). Quando baseado em pontos de corte masculinos, 3 a $6 \%$ dos homens tiveram osteoporose e 28 a $47 \%$ tiveram osteopenia. Por outro lado, quando baseado em pontos de corte femininos, a osteoporose esteve presente em $1-4 \%$ e a osteopenia em $15-33 \%$ dos homens. Este trabalho de Looker e col. (1997) apresenta as dificuldades de utilização do critério diagnóstico para osteoporose, proposto pela Organização Mundial de Saúde, para populações masculinas.

A osteoporose pode ser classificada em dois grupos: primária, na qual as causas fundamentais não são bem conhecidas; e secundária, quando relaciona-se com doenças e estados que alteram o metabolismo ósseo (Borelli 1994).

A mais comum é a osteoporose primária, nas formas pósmenopausal e a senil, esta última encontrada tanto em homens como em mulheres. A perda óssea relativa à idade é um fenômeno bem conhecido. Alguns idosos podem desenvolver osteoporose aparentemente clínica com fraturas, deformidades e dores. Outros pacientes idosos mantêm-se assintomáticos, podendo apresentar somente algum grau de perda de estatura e curvatura aumentada na coluna vertebral (Wingate 1984).

Os fatores que predispõem à osteoporose são aqueles que induzem a um baixo pico de massa óssea e aqueles que induzem a uma perda óssea excessiva associada à pós-menopausa e ao envelhecimento. $\mathrm{O}$ risco de fratura 
por fragilidade é dependente da quantidade e da densidade da massa óssea alcançada no adulto jovem e na taxa de perda óssea subsequente. Os determinantes do pico de massa óssea não estão ainda bem definidos. Certamente, fatores genéticos são importantes. Fatores hormonais, ambientais e nutricionais também contribuem para a determinação do pico de massa óssea (NIH 1994, Branca 1997).

Os principais fatores de risco para osteoporose são: sexo, idade, raça, compleição física pequena, história familiar de osteoporose, menopausa precoce, tabagismo, sedentarismo, ingestão excessiva de café ou bebida alcóolica e dieta inadequada e/ou inapropriada (Wingate 1984; Amauld e Sanchez 1990; Nilas 1993; Borelli 1994; Dawson-Hugles 1995).

Em relação ao sexo, a prevalência de todas as fraturas é similar em homens e mulheres. Contudo, a maioria das fraturas por osteoporose ocorre em mulheres idosas, e as razões para isto são o menor pico de massa óssea das mulheres em relação aos homens, a acelerada perda de osso que ocorre nos primeiros anos pós-menopausa, e o fato de as mulheres viverem mais que os homens, o que as torna mais expostas ao risco de fratura (Kanis e Pitt, 1992).

Tanto a perda de massa óssea como a incidência de fraturas têm sido pouco estudadas nos homens. Isto pode ser associado à grande dimensão do problema nas mulheres, embora estudos recentes apontem que fraturas em homens ocorram mais comumente do que se esperava (Jacobsen e col. 1990; Orwoll e Klein 1995; Nguyen e col. 1996; Grisso e col. 1997). Em estudo sobre a incidência de fraturas de quadril em população idosa dos EUA, observou-se que $\mathrm{o}$ risco de fratura aumentava com a idade em ambos os sexos. Nos homens, a incidência encontrada foi de 0,9 por 1000 aos 65 anos e 26,0 por 1000 aos 96 anos (Jacobsen e col. 1990).

Até o momento, não existem dados sobre a densidade mineral óssea e sobre osteoporose em homens na população brasileira. 
As fraturas de quadril nos homens são responsáveis por maior mortalidade do que nas mulheres. As fraturas vertebrais são um problema menor em termos de morbidade, mortalidade e custo, mas são debilitantes e têm sido observadas comumente na prática clínica ( Seeman 1995). Como já exposto anteriormente, com o aumento da expectativa de vida $e$ as mudanças demográficas no mundo, a osteoporose poderá se tornar um dos maiores problemas de saúde pública, e de forma especial para a população masculina (Consensus Development Statement 1997).

A associação dos fatores dietéticos com osteoporose pode ocorrer devido ao insuficiente consumo de cálcio e vitamina $D$, malabsorção desses nutrientes, à interação negativa do cálcio com outros nutrientes ou devido à desnutrição protéico-calórica. Um baixo consumo de cálcio está associado a altas taxas de fraturas em todas as idades, e o baixo consumo crônico é maior em mulheres do que em homens. A retenção corporal de cálcio aumenta com o aumento de seu consumo. A desnutrição protéico-calórica moderada ou grave está associada com um decréscimo na massa óssea em crianças, o que pode vir a ser um fator predisponente quando adultos (Wingate, 1984).

Devido à morbidade, à redução da expectativa de vida e aos custos dos serviços de saúde, associados à presença de fraturas, uma das formas de intervenção mais apropriada é a prevenção da osteoporose. Algumas medidas gerais de saúde pública podem beneficiar toda a população e deveriam ser instituídas. Assim são recomendadas ingestão adequada de cálcio e vitamina D, exercícios regulares para aumento de tensão muscular, abandono do hábito de fumar e redução do consumo de bebidas alcóolicas. Estas medidas estão ligadas diretamente à diminuição da perda de massa óssea e, portanto, à redução do risco de fratura. Outras recomendações incluiriam a prevenção de quedas, a melhora das funções cognitivas e a proteção dos quadris (Zerbini 1998). 


\section{5) Densidade mineral óssea e consumo de cálcio} dietético:

Segundo o consenso sobre ingestão ótima de cálcio, o adequado consumo desse mineral é necessário para que um indivíduo maximize o pico de massa óssea, quando adulto jovem; mantenha a massa óssea e minimize a perda óssea que acompanha o envelhecimento (NIH 1994).

O consumo deficiente de cálcio acarreta menor mineralização óssea, acentuando o processo de desmineralização que acompanha o envelhecimento (Heaney e col. 1982; Heaney 1991; Constants e col. 1994). Embora a carência de cálcio dietético não seja a única causa da osteoporose, o seu consumo é um dos poucos fatores passiveis de intervenção. Mas os efeitos das manipulações dietéticas ou da suplementação de cálcio sobre as taxas de perda óssea e de incidência de fraturas não são totalmente conclusivos.

Em estudo de revisão sobre a importância do cálcio na saúde e na doença, Nordin (1997b) discorreu sobre a essencialidade deste nutriente, mas também sobre os seus aspectos controversos e a inexistência de consenso sobre o nivel de necessidade humana de cálcio e o significado de sua deficiência.

O papel da deficiência de cálcio na patogênese da osteoporose humana tem sido objeto de controvérsia desde 1885, quando surgiu na literatura a primeira diferenciação entre osteoporose e osteomalácia. Pommer (1885) apontou que osteoporose era uma diminuição de todo tecido ósseo sem mudança no seu conteúdo mineral, e osteomalácia representava uma falha na mineralização do processo de formação óssea como conseqüência de deficiência de cálcio. Poucos anos após a apresentação deste estudo, Miwa e Stoeltzner (1898) demonstraram que a deficiência de cálcio causava osteoporose, não osteomalácia, em animais adultos experimentais. 
Como mencionado anteriormente, $99 \%$ do cálcio corporal encontram-se nos tecidos duros: dentes e ossos. A necessidade de cálcio é largamente determinada pelas necessidades esqueléticas e a quantidade de osso que pode ser acumulada é limitada pela quantidade de cálcio ingerida. Desta forma, uma deficiência de cálcio faz-se sentir de forma mais marcante sobre estas estruturas. A pequena parcela de cálcio nos fluidos extracelulares atua sobre a homeostase do cálcio como um todo. $\mathrm{O}$ organismo necessita manter a concentração plasmática de cálcio para a proteção dos sistemas neuromuscular e de coagulação sangüínea. Em situações de hipocalcemia, o cálcio é reabsorvido do esqueleto, por processo mediado pelo paratormônio, para compensar baixo consumo dietético e falhas na absorção intestinal de cálcio ou na sua excreção (Nordin e Morris 1989; Fujita 1997).

Pequenas flutuações, em relação à adequada área de reserva de cálcio, não têm significado estrutural prático. Contudo, de forma prolongada o desequilibrio na remoção de cálcio das reservas esqueléticas pode produzir conseqüências estruturais como a perda rápida de osso e a fragilidade esquelética. Por causa do efeito acumulado por vários anos da remoção de cálcio do osso para os fluidos extraesqueléticos, a freqüência de fraturas osteoporóticas tende a subir com a idade. Mas ao se discutir o efeito da homeostase do cálcio sobre a densidade mineral óssea, não se pode omitir que a redução da massa óssea não é o único fator de fragilidade osteoporótica, e que o baixo consumo de cálcio não é o único fator causador da redução da massa óssea (Heaney 1997).

Quando o efeito do cálcio é comparado ao do estrógeno em relação à densidade mineral óssea, observa-se que, no período pós-menopausal imediato, o estrógeno, que tem ação direta no osso, tem sido mais eficiente do que o cálcio na manutenção da integridade óssea. A maioria dos trabalhos tem demonstrado um efeito positivo da suplementação com cálcio, com resultados intermediários aos grupos não tratados e tratados com estrógeno ( Horsman e col. 1977; Recker e col. 1987; Nordin e Heaney 1990; Fujita 1997). A evidência de que o tratamento com estrógeno é adequado na prevenção da perda óssea é conclusiva, mas o mesmo não pode ser afirmado sobre o papel do consumo 
de cálcio dietético e os valores recomendados de cálcio suplementar (Nordin e Heaney 1990).

Meunier e col. (1994), estudando o efeito da suplementação de cálcio e vitamina $D$ em idosos institucionalizados, observaram aumento da densidade mineral óssea e diminuição da freqüência de fratura de quadril. Resultados semelhantes foram observados por Chapuy e col. (1992) em estudo com 3270 mulheres idosas institucionalizadas (idade média de 84 anos e desvio padrão de 6 anos), sendo que 1636 idosas participaram do grupo placebo e 1634 receberam suplementação de 800 UI de vitamina D e 1,2 g de cálcio elementar. Este último estudo demonstrou que a suplementação com vitamina $D_{3}$ e cálcio aumentou a densidade mineral óssea do fêmur proximal e reduziu o risco de fratura de quadril e de outras fraturas não localizadas na coluna em mulheres idosas. Esses dois estudos demonstraram que a idade avançada não é um fator impeditivo à prevenção de fraturas de quadril.

Os resultados das pesquisas sobre a relação entre consumo de cálcio dietético e massa óssea são conflitantes. O estudo epidemiológico de Matkovic e col. (1979) encontrou massa óssea significantemente maior em uma região da lugoslávia com maior consumo de cálcio, quando comparada a outra região desse mesmo país, porém com menor consumo de cálcio. Este estudo deu origem a vários outros que relacionaram deficiência de cálcio com osteoporose. Em estudo prospectivo com 522 mulheres sem alteração na densidade mineral óssea, observou-se fraca correlação entre o consumo de cálcio e a perda óssea (Nordin e Polley 1987). Outro estudo prospectivo demonstrou relação entre o consumo de cálcio dietético e perda óssea somente no úmero e não no rádio (Freudenheim e col. 1986). Dawson-Hughes e col. (1987) observaram maior velocidade de perda óssea na coluna em 19 mulheres com consumo de cálcio abaixo de $400 \mathrm{mg}$ do que em 19 mulheres com consumo maior do que $770 \mathrm{mg}$ de cálcio. Riggs e col. (1987) não encontraram correlação entre consumo de cálcio dietético e perda óssea em 106 mulheres na pré e na pós-menopausa. Já Sinake e col. (1989) encontraram correlação negativa entre consumo de cálcio dietético e densidade mineral na coluna em 64 mulheres após a menopausa. 
Como demonstrado pela breve exposição das pesquisas anteriormente citadas, ainda não são conclusivas as relações entre consumo de cálcio dietético e perda óssea. Nordin e Heaney (1990) apresentaram que as prováveis maiores razões para esta controvérsia são as diferenças e erros na colheita da história dietética e aceitação de que o consumo dietético atual de cálcio seja o mesmo da média real de consumo ao longo da vida.

Atentando para as conseqüências em saúde púbica, a massa óssea por si só é menos importante do que as fraturas, e é na prevenção destas que a evidência dos efeitos do cálcio é mais forte. Alguns trabalhos buscaram comprovar esta relação entre consumo de cálcio e fraturas. Matkovic e col. (1979) observaram que a incidência de fraturas de quadril era 60 a $75 \%$ menor em mulheres com consumo médio de cálcio dietético de $1000 \mathrm{mg} /$ dia quando comparadas às mulheres com metade deste consumo. Em estudo feito em Hong Kong, houve uma significativa relação negativa entre consumo de cálcio e fraturas de quadril (Lau e col. 1988). Estudo prospectivo de Holbrook e col. (1988) encontrou taxa de fratura de quadril $60 \%$ menor em homens e mulheres no tercil superior de consumo (acima de $765 \mathrm{mg} / \mathrm{dia}$ ), quando comparado aos participantes no menor tercil de consumo (abaixo de $470 \mathrm{mg} / \mathrm{dia}$ ). Já na Inglaterra, foi possivel observar esta relação entre consumo de cálcio dietético e fratura de quadril somente em homens e não em mulheres (Cooper e col. 1988).

Kanis e Passmore (1989), abordando o mesmo tema de Nordin e Heaney (1990), ou seja, a suplementação de cálcio na dieta, apontam que vários fatores de confusão impedem a efetiva avaliação dos efeitos terapêuticos do cálcio no curso natural da perda óssea senil, como a atividade física e consumo calórico. Esses autores apontam ainda que, apesar de não considerarem totalmente convincentes as evidências dos efeitos do cálcio sobre as taxas de perda óssea e de incidência de fratura, acreditam que o cálcio tenha algum efeito. $E$ considerando que o seu efeito seja apenas $1 \%$ mais efetivo que o grupo placebo na redução na incidência de fraturas, isto poderia prevenir mais do que 1000 fraturas por ano na Inglaterra, o que já se caracteriza como uma importante medida em saúde pública. 
Com base em levantamentos epidemiológicos e alguns estudos clínicos, autores têm considerado o consumo aumentado de cálcio justificável, seguro e, possivelmente, eficaz na prevenção da perda óssea, principalmente em mulheres após a menopausa, recomendando um aumento do cálcio da dieta para 1000 a 1500 mg/dia (Allen 1986; Arnauld e Sanchez 1990; Borelli 1994; Lindsay 1995).

O Consenso do National Institutes of Health, realizado em 1994, sobre consumo de cálcio, considerou os dados recentes de doenças relacionadas ao cálcio, em especial a osteoporose. Os dados finais da conferência sugerem que o consumo de cálcio deve ser de $1000 \mathrm{mg} / \mathrm{dia}$ para mulheres na pós-menopausa com terapia de reposição de estrogênio e 1500 mg/dia para mulheres na pós-menopausa sem terapia de reposição. Para homens, na idade de 25 a 65 anos, o consumo diário recomendado seria de $1000 \mathrm{mg}$. Para homens e mulheres acima de 65 anos, consumo de 1500 $\mathrm{mg} / \mathrm{dia}$, uma vez que a fisiologia do cálcio em homens acima de 65 anos é semelhante à da mulher nesta mesma faixa etária, em relação à taxa de perda óssea, eficiência da absorção do cálcio e declínio do nível de vitamina D. (NIH 1994).

A natureza insidiosa, bem como as possibilidades terapêuticas limitadas e de alto custo, realçam a necessidade da prevenção do aparecimento da osteoporose. Do conhecimento dos fatores de risco decorrem as medidas preventivas gerais, como aumento da ingestão de cálcio, exercício físico e reposição hormonal (Wingate 1984; Heaney 1991; Odell e Heath 1993; Borelli 1994). 


\section{6) Justificativa do estudo:}

Devido à importância do cálcio no metabolismo corporal e na manutenção da saúde, tem surgido a necessidade de estudos sobre o consumo de cálcio dietético em nivel populacional. Vários países já desenvolvem pesquisas nesta área, contudo em nosso meio existem poucos dados sobre o consumo de cálcio de brasileiros e suas implicações na densidade mineral óssea e, consequentemente, seu papel na etiologia, prevenção e tratamento da osteoporose.

Além disso, ainda não dispomos, no Brasil, de pesquisas sobre a densidade mineral óssea em homens e sua relação com aspectos dietéticos. $A$ magnitude do problema da osteoporose e das fraturas por fragilidade é maior em mulheres do que em homens (Johnell e col. 1992; Kanis e Pitt 1992; Elffors e col. 1994; Looker e col. 1997; Mautalen e Pumarino 1997). Entretanto, tem havido, nesta década, aumento do interesse sobre a epidemiologia da osteoporose em homens, e as pesquisas, apesar do pequeno número, têm apontado essa doença, na população masculina, como um importante e crescente problema de saúde pública (Jacobsen e col. 1990; Orwoll e Klein 1995; Nguyen e col. 1996; Grisso e col. 1997).

Foi com este intuito que realizou-se o presente estudo, buscando identificar as relações do consumo de cálcio dietético com a densidade mineral óssea em indivíduos adultos e idosos do sexo masculino. 
2 - OBJETIVOS 


\section{1) Objetivo geral:}

Verificar as relações entre o consumo de cálcio dietético e a densidade mineral óssea em homens adultos e idosos.

\section{2) Objetivos especifficos:}

- Analisar a adequação do consumo de cálcio dietético atual e pregresso.

- Avaliar as fontes de cálcio dietético consumidas.

- Verificar as correlações existentes entre o consumo de cálcio dietético atual e a densidade mineral óssea na coluna lombar, colo do fêmur e conteúdo de cálcio corporal total .

- Analisar as diferenças de médias da densidade mineral óssea nos grupos de consumo de cálcio dietético atual, definidos segundo alcance da recomendação.

- Analisar as diferenças de médias da densidade mineral óssea nos

grupos de consumo de cálcio dietético pregresso, definidos conforme adequação. 
3 - METODOLOGIA 
O presente estudo está inserido em uma pesquisa ampla intitulada "Avaliação clínica dos fatores de risco para osteoporose em homens" desenvolvido pelo Serviço de Reumatologia do Hospital Heliópolis, em conjunto com os Departamentos de Nutrição e Epidemiologia da Faculdade de Saúde Pública da Universidade de São Paulo (USP). Este estudo foi aprovado pela Comissão de Ética Médica do Hospital Heliópolis (Anexo 1).

A equipe que desenvolveu a pesquisa citada foi composta por três médicos, uma nutricionista (autora do presente estudo), um professor de educação física, uma técnica em densitometria óssea e uma secretária.

O Hospital Heliópolis é um hospital público estadual, fundado em 1969, e presta assistência em saúde nas diversas especialidades médicas. Está situado na região sul da cidade de São Paulo, na divisa com o município de São Caetano do Sul. Sua área de abrangência inclui a região sul da cidade de São Paulo e as cidades Santo André, São Bernardo do Campo, São Caetano do Sul e Diadema. Para este estudo foram aceitos pacientes que residiam fora da área de abrangência do hospital.

\section{1) Delineamento do estudo:}

Este estudo é do tipo transversal, observacional, abrangendo indivíduos voluntários do sexo masculino.

\section{2) População de estudo:}

Foram recrutados 357 indivíduos voluntários do sexo masculino com idade igual ou superior a 50 anos. $O$ recrutamento foi feito através da imprensa, avisos colocados no posto de atendimento médico do Hospital Heliópolis e através de conhecidos dos membros da equipe. Cônjuges de mulheres que compareceram para densitometria óssea e funcionários do complexo hospitalar também foram convidados a participar da pesquisa. 
A população foi composta por indivíduos que se submeteram ao exame de densitometria óssea no período de fevereiro a agosto de 1997, no Posto de Atendimento Médico (PAM) Heliopólis. Este serviço está sob supervisão do Serviço de Reumatologia do Hospital Heliópolis.

Os critérios de exclusão estabelecidos foram a presença de qualquer patologia concomitante, ingestão de medicamentos que pudessem afetar o metabolismo ósseo ou causar osteoporose, e estatura superior a 1,90 metros, devido à limitação de visibilidade do corpo no aparelho de densitometria.

Antes da realização do exame os pacientes assinaram um termo de consentimento informado do paciente (anexo 2).

Foram programadas duas visitas por participante. Na primeira visita foram colhidos os dados da anamnese clínica, feitos os exames de densitometria óssea (realizados pelos médicos e pela técnica em densitometria óssea), avaliação antropométrica e de composição corporal, e orientação para preenchimento do diário alimentar (procedimentos realizados pela nutricionista). Na segunda visita, os participantes devolveram 0 diário alimentar, receberam os exames analisados e foram orientados de acordo com os resultados, sendo as orientações feitas pelos médicos e pela nutricionista.

\section{3) Variáveis de estudo:}

\subsection{1) Densidade mineral óssea:}

O exame de densitometria óssea foi realizado em todos os participantes da pesquisa, com um densitômetro de dupla emissão de raios $X$ (Lunar Corp., Madison, WI) e analisados com o programa (software) Lunar versão 3.1. Antes de cada sessão era realizado o controle de qualidade do 
aparelho, que era calibrado com um "standard phantom". O coeficiente de variação para as medidas densitométricas na Unidade de Densitometria Óssea do PAM Heliópolis é de $1,5 \%$ para a coluna lombar e de $2,0 \%$ para a região proximal do fêmur.

Foram feitas as medições da densidade mineral óssea (DMO) na região proximal do fêmur (colo do fêmur) na coluna lombar (L2-L4) e de corpo inteiro, assim como a medição do conteúdo corporal total de cálcio.

\subsection{2) Consumo de cálcio dietético:}

O consumo de cálcio dietético foi avaliado no momento atual (no período do estudo) e pregresso (ao longo da vida).

\subsubsection{1) Consumo de cálcio dietético atual:}

Para identificar o consumo de cálcio dietético atual (CCD atual) da população através de inquérito alimentar, foi utilizado o método de registro de consumo de alimentos, também denominado diário alimentar. Neste método, o respondente é solicitado a registrar todos os alimentos e bebidas consumidos, estimando o tamanho das porções em medidas caseiras após terem sido instruidos sobre a forma de anotação de todos os registros (Dwyer 1988).

Os alimentos consumidos foram registrados em todas as refeiçöes do dia, em três dias intercalados, sendo um deles referente ao fim de semana (sábado ou domingo). Adotou-se esta metodologia para minimizar possiveis diferenças existentes entre as dietas por variação diária no padrão de consumo.

$O$ instrumento de registro do consumo de alimentos (anexo 3 ) foi distribuido e orientou-se os participantes sobre o preenchimento. Foram ressaltados os cuidados necessários ao preenchimento, como: 
1) anotar o dia da semana (segunda, terça, quarta, quinta, sexta, sábado ou domingo) e a data na ficha de registro de consumo de alimentos.

2) especificar todos os alimentos que foram ingeridos em cada dia, anotando os tipos e marcas dos produtos industrializados.

3) anotar as quantidades, usar medidas caseiras completas como: colheres (de sopa, de sobremesa, de chá e de café) rasa, média ou cheia, concha, escumadeira (especificando se rasa, média ou cheia), unidade (pequena, média ou grande).

Exemplos: leite em pó Ninho - 2 colheres de sopa cheias, e queijo tipo mussarela - 1 fatia média

4) Incluir no item "observações" do formulário ingredientes utilizados em preparação mais sofisticadas:

Exemplo: batata ao molho branco - batata cozida, leite tipo $\mathrm{C}$, maisena, sal, margarina e outros.

Todos os participantes receberam um manual com instruções para o preenchimento do registro de consumo de alimentos (anexo 4). Desta forma, aqueles participantes que não sabiam escrever e que dependiam de ajuda de familiares para o preenchimento do registro de consumo de alimentos, puderam ter anotado o seu consumo de forma adequada, sem prejuízo da orientação direta da nutricionista.

Após o preenchimento, os formulários foram devolvidos em data previamente agendada. De posse dos diários alimentares, O CCD atual foi definido pela quantidade média de cálcio consumida e pela identificação das principais fontes de cálcio.

A quantidade de cálcio foi calculada, utilizando o Sistema de Análise Nutricional - Virtual Nutri, desenvolvido por Philippi e col. (1996) do Departamento de Nutrição da Faculdade de Saúde Pública da USP, que oferece uma grande variedade de alimentos "in natura", industrializados e preparações, incluindo as típicas brasileiras que não poderiam ser encontradas facilmente em outros programas. As informações obtidas em medidas caseiras foram convertidas em gramas através dos padrões sugeridos pelo sistema 
mencionado, que garante confiança uma vez que as medidas são resultantes de pesquisas em laboratório de técnica dietética.

O consumo médio de cálcio foi definido pela média aritmética das quantidades de cálcio dos três dias de registro de consumo alimentar.

A avaliação da adequação do consumo de cálcio foi realizada pela comparação entre a média aritmética das quantidades de cálcio dos registros e a recomendação estabelecida pelo National Research Council (NRC), em 1989, que é de $800 \mathrm{mg} /$ dia desse nutriente para pessoas com 51 anos e mais.

Considerando que alguns autores (Vir e Love 1978; O'Hanlon e Kohes 1978) definem que a adequação de nutrientes será atendida quando o seu consumo atinge $2 / 3$ da recomendação, distribuiu-se a população em 3 grupos de consumo conforme alcance da recomendação:

- menor do que $2 / 3$ da recomendação ( $<533 \mathrm{mg} / \mathrm{dia}$ ),

- igual ou maior a 2/3 e menor do que a recomendação (533 a 799 mg/dia), - igual ou maior a recomendação (= ou > $800 \mathrm{mg} / \mathrm{dia}$ ).

Na determinação das fontes de cálcio, consideram-se três aspectos: a quantidade do nutriente no alimento, o tamanho da porção habitualmente consumida e a biodisponibilidade do nutriente.

Em relação aos aspectos quantitativo e de tamanho da porção tomou-se como orientação o conceito de Bing e col. 1937: quando 1/10 das recomendações diárias de um nutriente é fornecido por uma porção de alimento facilmente ingerida em um dia, esse alimento pode ser considerado uma fonte do nutriente em questão. Desta forma, foi realizada pesquisa em tabelas de composição de alimentos e sistema de análise nutricional, Virtual Nutri (IBGE 1977; Franco 1992; Philippi e col. 1996; Pinheiro e col. 1996), para listagem dos alimentos que oferecem $1 / 10$ da recomendação de cálcio, ou seja, $80 \mathrm{mg} \mathrm{em} 100 \mathrm{~g}$ do alimento. Também foi considerada a recomendação estabelecida pelo NRC, em 1989. 
Os alimentos listados foram então analisados em relação ao tamanho da porção, sendo excluídos os que não ofereciam $80 \mathrm{mg}$ de cálcio em uma porção habitualmente ingerida. As porções foram determinadas, estabelecendo-se um percentual de $20 \%$ a mais e a menos a partir de porções pesquisadas na literatura (Silva e Monnerat 1986; Philippi e col. 1996; Pinheiro e col. 1996). A tabela desenvolvida das fontes alimentares de cálcio dietético, segundo quantidade do nutriente e tamanho da porção, encontra-se em anexo (Anexo 5).

Uma vez estabelecida a lista de alimentos fontes de cálcio de acordo com os aspectos quantitativo e de porção, foi feita então a análise dos diários alimentares para identificação das fontes e a distribuição por freqüência percentual de consumo. Os alimentos fontes foram distribuídos nos seguintes grupos:

- leites,

- queijos e requeijão,

- iogurtes,

- doces e sobremesas,

- hortaliças,

- peixes e frutos do mar,

- preparaçōes lácteas,

- outras preparações.

Após a distribuição dos alimentos fontes de cálcio por freqüência percentual de consumo, foi feito o estudo da biodisponibilidade do nutriente nos diferentes grupos estabelecidos. Fez-se este estudo, tendo em vista a literatura que menciona a biodisponibilidade do cálcio do leite e seus substitutos como superior a dos outros alimentos. As hortaliças apesar de possuirem quantidade de cálcio que atenda a 1/10 da recomendação por porção habitualmente consumida, podem ter sua biodisponibilidade comprometida pela presença de ácidos oxálicos e fíticos, que se combinam com o cálcio, formando sais insolúveis e prejudicando sua absorção (Heaney e col. 1990; Charles 1992; Weaver 1992; NIH 1994; Nordin 1997a; Miller 1997). 


\subsubsection{2) Consumo de cálcio dietético pregresso:}

O consumo de cálcio dietético pregresso foi avaliado retrospectivamente através de um questionário de frequência de consumo de leite e substitutos: queijo, coalhada e iogurte (anexo 6 ). 0 consumo destes alimentos foi investigado em três fases: 10 a 20 anos, 21 a 30 anos, 31 a 49 anos.

Baseado no trabalho de Sandler e col. (1985) e na recomendação do NiH (1994) para fontes preferenciais de cálcio, limitou-se as fontes de cálcio investigadas ao leite e seus substitutos, já que estas são suas fontes primárias, ou seja, apresentam maior quantidade e melhor biodisponibilidade do cálcio.

Em função das dificuldades metodológicas de precisão quantitativa do consumo de cálcio ao longo da vida e dos conseqüentes problemas de avaliação, considerou-se adequado o consumo diário de cálcio e inadequado nas outras freqüências de consumo, para o período correspondente.

\subsection{3) Idade:}

A idade cronológica dos individuos foi calculada com base na data de nascimento e na data da realização dos exames.

Foram avaliadas quatro fases cronológicas: 10 a 20 anos, 21 a 30 anos, 31 a 49 anos e 50 anos e mais.

\subsection{4) Outras variáveis:}

Todos os participantes responderam um questionário (anexo 7) sobre as suas características demográficas, sociais, físicas e médicas. 
Neste questionário, foram investigadas possiveis variáveis determinantes da DMO, conforme relatos na literatura (Dequeker e col. 1991; Kanis e Pitt 1992; Krall e Dawson-Hughes 1993; Nguyen e col. 1994; Glynn e col. 1995; Salamone e col. 1995; Nguyen e col. 1996). Constava de dados pessoais do participante, história familiar de fratura e antecedentes mórbidos, hábito de fumar, consumo de álcool e dados sobre a utilização de diuréticos tiazídicos, anti-convulsivantes, suplementos de cálcio e vitamina $D$, uso de glicocorticóides, além de avaliação antropométrica e de composição corporal, e do grau de atividade física. Contudo, para o presente estudo foram consideradas apenas algumas variáveis demográficas ( idade, cor, estado civil e escolaridade).

\section{4) Análise estatística:}

Primeiramente, as variáveis foram analisadas de forma descritiva por meio de médias, desvios padrão, valores mínimo e máximo, e mediana.

Para verificar a correlação entre a densidade mineral óssea e o consumo de cálcio dietético atual foi calculado o coeficiente de correlação de Pearson $(r)$.

Para avaliação das diferenças de médias dos dados da densitometria nos grupos conforme adequação do consumo de cálcio dietético no passado, e nos grupos conforme alcance da recomendação do consumo de cálcio dietético atual foi utilizado o teste de diferença de médias de $t$-Student e Kruskal-Wallis.

Em todas as análises foi adotado o nivel de significância $\alpha=5 \%$. 


\section{5) Programas de computador:}

Para avaliação dos registros dietéticos de três dias foi utilizado o Sistema de Análise Nutricional - Virtual Nutri (Philippi e col. 1996).

Para as análises estatísticas foram utilizados os seguintes pacotes :

- Fox-Pro para Windows: digitação do banco de dados.

- Epi-Info versão 6.04: análise descritiva e teste de diferença de médias.

- SPSS para Windows versão 5.02: análise de correlação. 
4 - RESULTADOS 
Participaram da pesquisa 357 pacientes, destes 61 foram excluídos do presente estudo em função da ausência total ou parcial de dados do inquérito alimentar e da densitometria óssea, perfazendo $17 \%$ da população inicial. Em relação ao inquérito alimentar, 58 pacientes (16\%) não devolveram os formulários de registro alimentar ou o fizeram com preenchimento inadequado. Ao final, restaram 296 indivíduos que compuseram a população para este estudo.

Tabela 2: Distribuição numérica e percentual da população estudada, segundo as características demográficas. Hospital Heliópolis. São Paulo, 1997.

\begin{tabular}{l|rc}
\hline Característica & \multicolumn{2}{|c}{ Freqüência } \\
\cline { 2 - 3 } & $\mathrm{N}^{\circ}$ & $\%$ \\
\hline Idade: & 126 & 42,6 \\
$50-59$ anos & 109 & 36,8 \\
$60-69$ anos & 55 & 18,6 \\
$70-79$ anos & 6 & 2,0 \\
$80 \mathrm{e}+$ & & \\
Cor: & 238 & 80,4 \\
Branca & 28 & 9,5 \\
Preta & 28 & 9,5 \\
Parda & 2 & 0,6 \\
Amarela & & \\
& 10 & 3,4 \\
Estado civil: & 257 & 86,8 \\
Solteiro & 13 & 4,4 \\
Casado & 16 & 5,4 \\
Separado & & \\
Viúvo & & 2,0 \\
Escolaridade: & 6 & 35,8 \\
Analfabeto & 106 & 35,5 \\
Sabe ler e escrever & 105 & 13,2 \\
$1^{\circ}$ grau incompleto & 39 & 0,6 \\
$1^{\circ}$ grau completo & 2 & 8,0 \\
$2^{\circ}$ grau incompleto & 24 & 4,6 \\
$2^{\circ}$ grau completo & 14 & 100 \\
nivel superior & & \\
& & \\
\hline TOTAL & 296 & \\
\hline
\end{tabular}


Conforme demonstrado na tabela 2, a população de estudo foi composta por 296 homens com 50 anos e mais, a maioria de cor branca $(80,4 \%)$, casada $(86,8 \%)$ e com nível de escolaridade até o $1^{\circ} \mathrm{grau}$ incompleto $(73,3 \%)$. Na distribuição por idade, observa-se o predomínio de participantes na faixa etária de 50 a 59 anos (42,6\%) e 60 a 69 anos (36,8\%). A idade média foi de 62,5 anos (DP=7,9 anos).

Foi feita avaliação do consumo de cálcio dietético na população estudada, em dois momentos: consumo atual e pregresso. A tabela 3 apresenta a distribuição da população segundo adequação do consumo de cálcio dietético atual e pregresso.

Tabela 3: Distribuição numérica e percentual da população segundo adequação do consumo de cálcio dietético atual e pregresso. Hospital Heliópolis. São Paulo, 1997.

\begin{tabular}{l|cc|cc|cc}
\hline \multirow{2}{*}{\multicolumn{1}{c|}{ Idade }} & \multicolumn{6}{c}{ Consumo de cálcio dietético } \\
\cline { 2 - 8 } & \multicolumn{2}{|c|}{ Adequado } & \multicolumn{2}{c}{ Inadequado } & \multicolumn{2}{c}{ Ignorado } \\
\cline { 2 - 8 } & $\mathrm{N}$ & $\%^{*}$ & $\mathrm{~N}$ & $\%^{*}$ & $\mathrm{~N}$ & $\%$ \\
\hline Pregresso: & 186 & 64,8 & 101 & 35,2 & 9 & 3,0 \\
10 a 20 anos & 182 & 62,9 & 107 & 37,1 & 7 & 2,4 \\
21 a 30 anos & 188 & 66,9 & 93 & 33,1 & 15 & 5,1 \\
& & & & & & \\
Atual & 830 anos & 28,0 & 213 & 72,0 & -- & -- \\
\hline
\end{tabular}

* \% calculada com exclusão dos ignorados

Em relação ao CCD atual, a média do consumo foi de $696,2 \mathrm{mg} /$ dia (DP=333,8 mg/dia), variando de 118,7 a $2288,6 \mathrm{mg} / \mathrm{dia}$. Considerando-se a recomendação do NRC (1989), apenas $28 \%$ da população conseguiu alcançála. A maioria (72\%) dos homens consumiu menos do que $800 \mathrm{mg}$ de cálcio/dia, como demostrado na figura 1. 
Figura 1: Distribuição percentual da população segundo adequação do CCD atual, considerando recomendação do NRC/1989. Hospital Heliópolis, 1997.

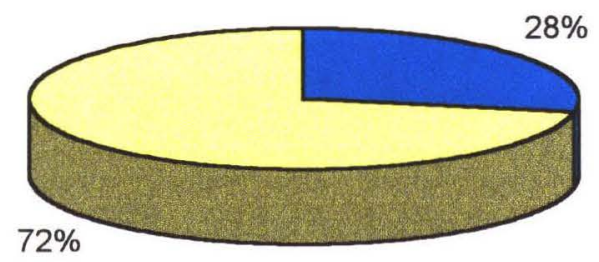

Adequado $\square$ Inadequado

O CCD atual, quando comparado ao CCD pregresso, teve maior inadequação. $\mathrm{O}$ consumo de cálcio dietético avaliado no passado, apresentouse adequado em cerca de $65 \%$ e inadequado em $35 \%$ da população. Para o cálculo da distribuição percentual da população segundo adequação do CCD pregresso, foram excluídos os pacientes que apresentaram consumo ignorado. Não foi observada grande variação no consumo ao longo da vida (figura 2).

Figura 2: Distribuição percentual da população segundo adequação do CCD no passado. Hospital Heliópolis. São Paulo, 1997.

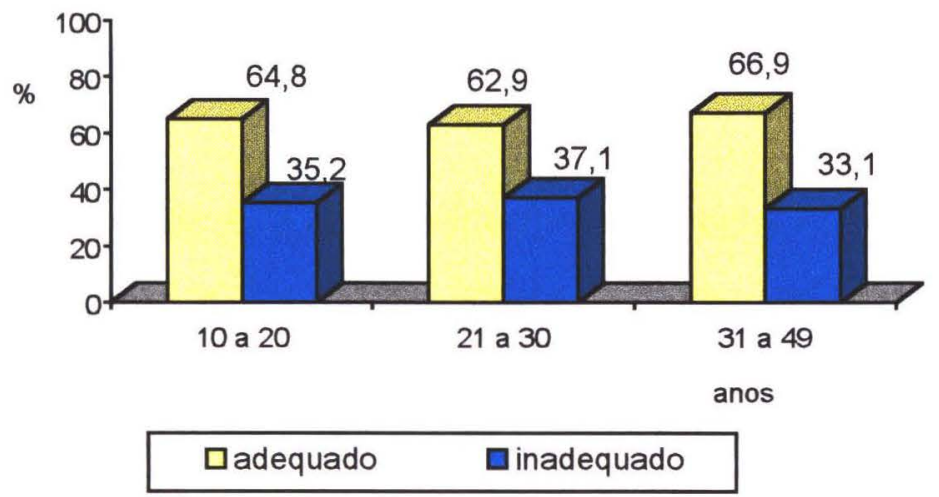


Considerando-se a distribuição da população de acordo com a classificação do CCD atual, segundo alcance da recomendação observou-se que $35,1 \%$ da população não alcançam nem ao menos $2 / 3$ da recomendação (figura 3).

Figura 3: Distribuição percentual da população estudada de acordo com a classificação do CCD atual, segundo alcance da recomendação do NRC/1989. Hospital Heliópolis. São Paulo, 1997.

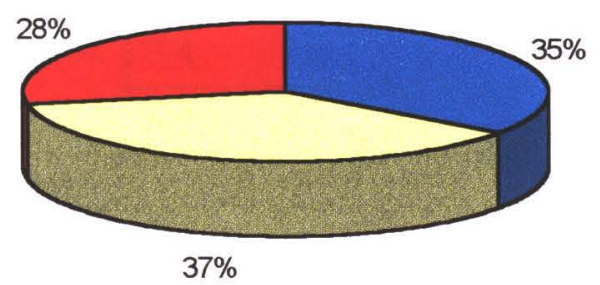

$\square<533 \mathrm{mg} / \mathrm{dia}$ प533 a $799 \mathrm{mg} / \mathrm{dia} \square>799 \mathrm{mgdia}$

Na população estudada, a suplementação medicamentosa de cálcio foi rara. A maioria dos participantes $(96,6 \%)$ referiu não fazer uso de suplemento de cálcio, enquanto apenas $2,7 \%$ referiram consumir e $0,7 \%$ não souberam informar.

$\mathrm{Na}$ avaliação das fontes alimentares de cálcio observou-se que o leite e os produtos e preparações lácteos foram as principais fontes consumidas pela população estudada, correspondendo a $93,7 \%$ na distribuição percentual por freqüência de consumo. O grupo dos leites foi o mais consumido dentre as fontes de cálcio, $62,8 \%$, conforme demonstrado pela figura 4 . 
Figura 4: Distribuição percentual das fontes de cálcio segundo freqüência de consumo. Hospital Heliópolis. São Paulo, 1997.

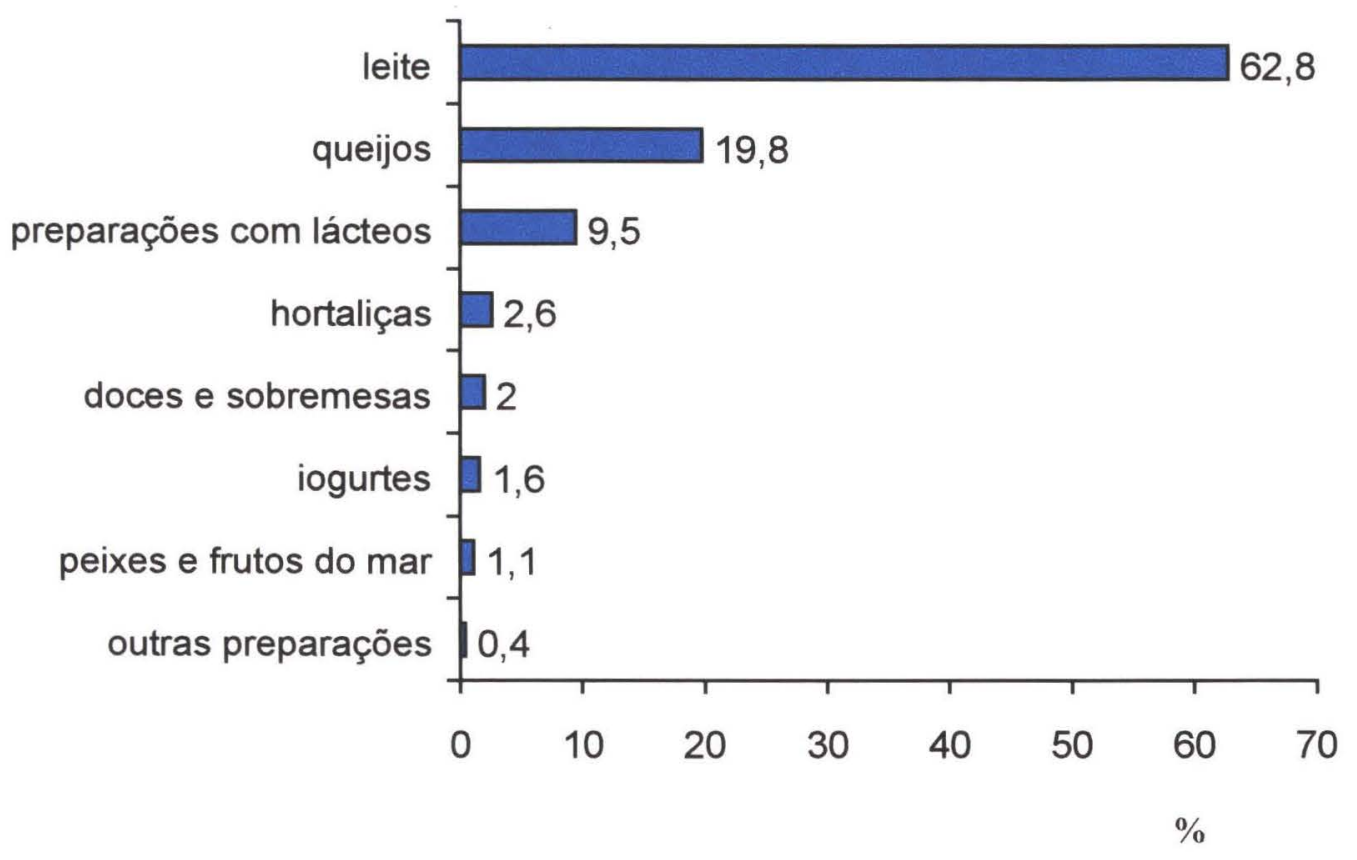

Já o grupo das hortaliças teve uma baixa freqüência de consumo $(2,6 \%)$, assim como o dos iogurtes $(1,6 \%)$ e dos peixes e frutos do mar que são fontes de cálcio $(1,1)$.

Como apresentado no capítulo anterior (metodologia), para este estudo foram considerados os dados de densidade mineral óssea (DMO) do colo do fêmur e coluna lombar, e o conteúdo de cálcio corporal total obtido pela densitometria de corpo total.

Os dados da densitometria óssea estão resumidos na tabela 4. Os valores médios de densidade mineral óssea (DMO), na coluna lombar e no colo do fêmur, também apresentaram uma grande variação. As médias da DMO na coluna foi $1,169 \mathrm{~g} / \mathrm{cm}^{2}$ (DP=0,193 $\mathrm{g} / \mathrm{cm}^{2}$ ), e no colo do fêmur foi $0,917 \mathrm{~g} / \mathrm{cm}^{2}$ $\left(\mathrm{DP}=0,145 \mathrm{~g} / \mathrm{cm}^{2}\right.$ ). O conteúdo de cálcio corporal total teve média de $1039,2 \mathrm{~g}$, variando de 514 a $1658 \mathrm{~g}$. 
Tabela 4: Características da população segundo dados da densitometria óssea. Hospital Heliópolis. São Paulo, 1997.

\begin{tabular}{c|c|c|c}
\hline Características & Média & $\begin{array}{c}\text { Desvio } \\
\text { padrão }\end{array}$ & $\begin{array}{c}\text { Mínimo- } \\
\text { máximo }\end{array}$ \\
\hline DMO $\left(\mathrm{g} / \mathrm{cm}^{2}\right):$ & 1,169 & 0,193 & $0,713-1,988$ \\
Coluna lombar & 0,917 & 0,145 & $0,538-1,393$ \\
Colo do fêmur & 1039,2 & 164,8 & $514-1658$ \\
\hline
\end{tabular}

Ao se correlacionar o CCD atual com os dados de DMO da coluna lombar, DMO do colo do fêmur e conteúdo de cálcio corporal total, só foi possível observar correlação em relação ao conteúdo de cálcio corporal total, conforme apresentado na tabela 5 e figuras 5,6 e 7 .

Tabela 5: Coeficiente de correlação entre $\operatorname{CCD}$ atual e dados da densitometria óssea na população estudada. Hospital Heliópolis. São Paulo, 1997.

\begin{tabular}{l|c|c}
\hline Característica & \multicolumn{2}{|c}{ CCD atual } \\
\cline { 2 - 3 } & $\mathrm{R}$ & $\mathrm{p}$ \\
\hline Densidade mineral da coluna lombar & 0,049 & 0,405 \\
Densidade mineral do colo do fêmur & 0,059 & 0,310 \\
Cálcio corporal total & $\mathbf{0 , 1 1 5 ^ { * }}$ & 0,047 \\
\hline
\end{tabular}

${ }^{*}$ Correlação significante quando $p<0,05$ 
Figura 5: Correlação entre DMO da coluna lombar e CCD atual, na população estudada. Hospital Heliópolis. São Paulo, 1997.

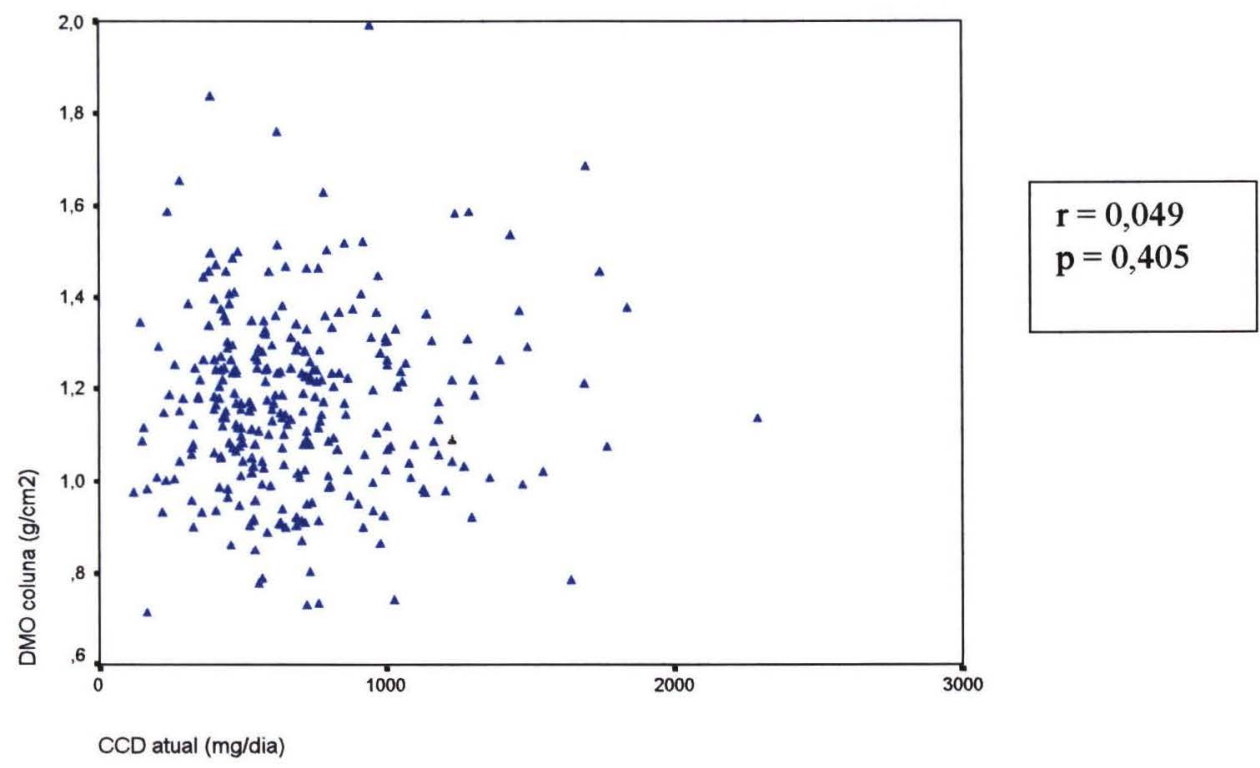

Figura 6: Correlação entre DMO do colo do fêmur e CCD atual, na população estudada. Hospital Heliópolis. São Paulo, 1997.

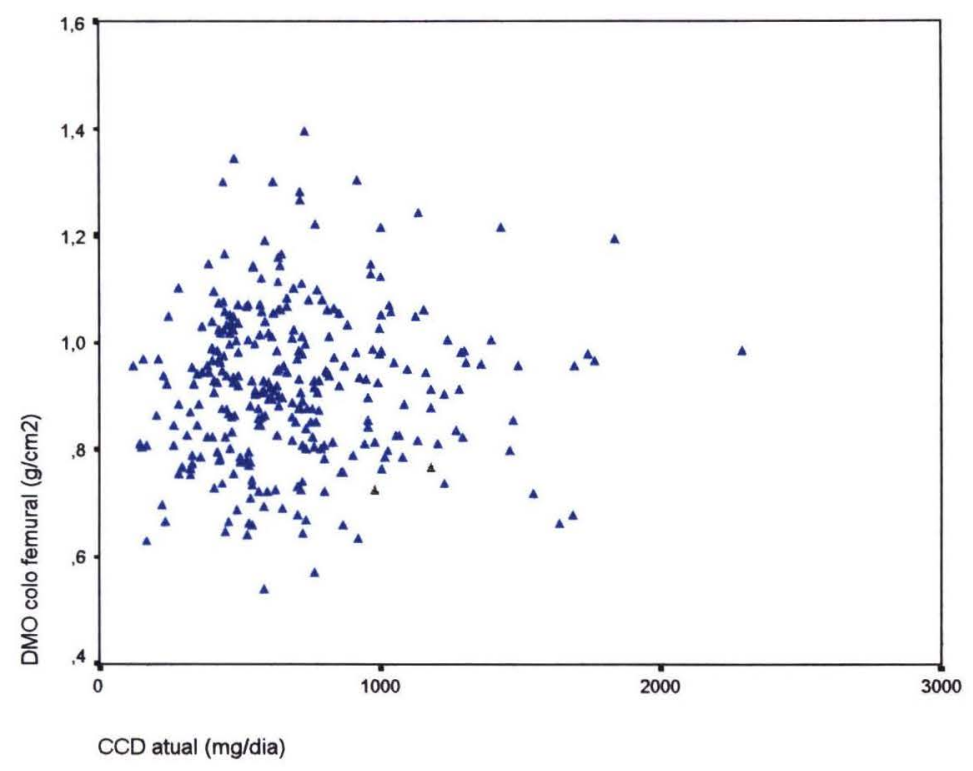


Figura 7: Correlação entre conteúdo de cálcio corporal total e CCD atual, na população estudada. Hospital Heliópolis. São Paulo, 1997.

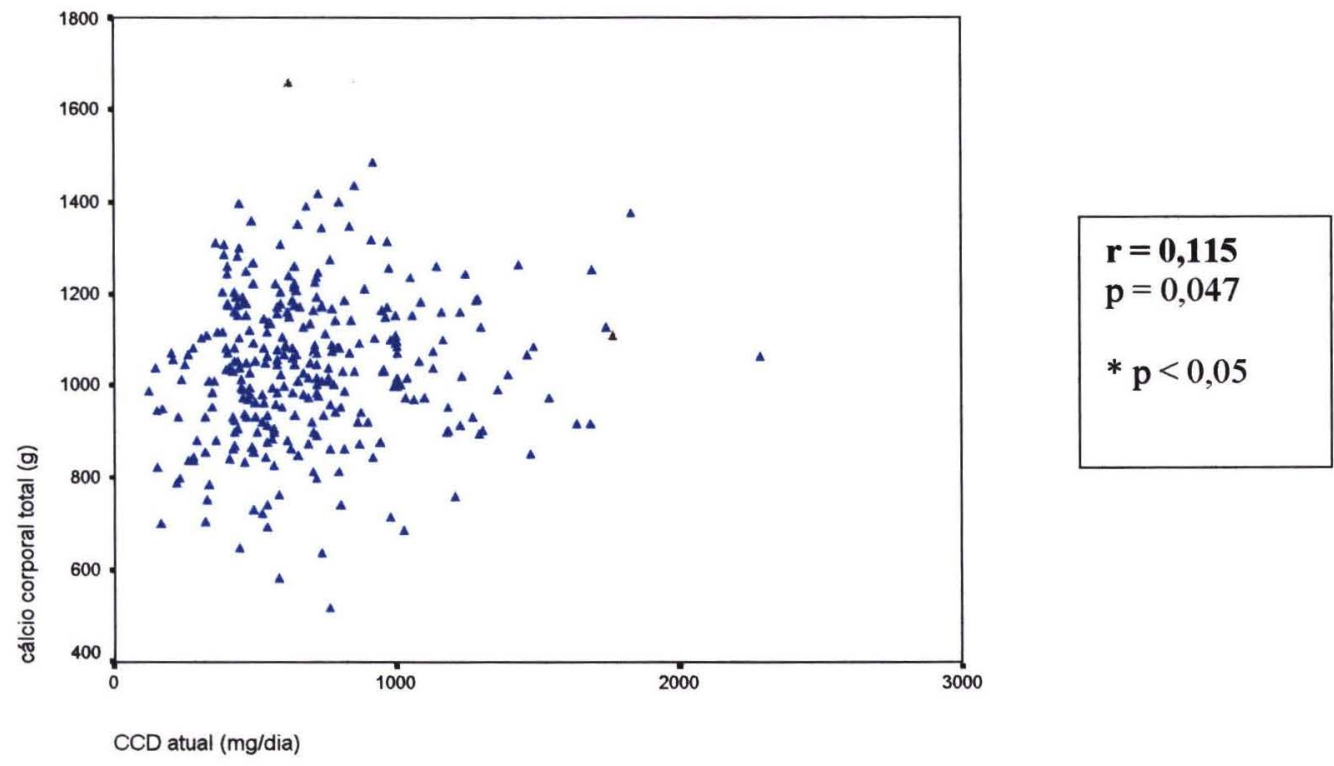

Avaliou-se as médias dos valores da densitometria nos três grupos de CCD atual, segundo alcance da recomendação.

Como demonstrado na tabela 6 , não houve diferença estatisticamente significativa $(p=0,323)$ entre as médias de DMO na coluna lombar nos três grupos de $C C D$ atual. $O$ mesmo se observou em relação às médias de DMO no colo do fêmur $(p=0,643)$ e conteúdo de cálcio corporal total $(p=0,198)$. Ou seja, não houve diferenças de DMO e de conteúdo de cálcio corporal entre os grupos de menor, intermediário e maior CCD atual. 
Tabela 6: Diferenças de médias, desvios padrão, valores mínimos e máximos e mediana dos valores da densitometria óssea nos três grupos de classificação do CCD atual conforme alcance da recomendação. Hospital Heliópolis. São Paulo, 1997.

\begin{tabular}{|c|c|c|c|c|c|}
\hline \multirow{2}{*}{$\begin{array}{l}\text { Caracte- } \\
\text { rísticas }\end{array}$} & \multirow[t]{2}{*}{ Parâmetro } & \multicolumn{3}{|c|}{$\begin{array}{l}\text { Consumo atual de cálcio dietético } \\
\text { ( } \mathrm{mg} / \mathrm{dia})\end{array}$} & \multirow[t]{2}{*}{$P$} \\
\hline & & $<533$ & $533-799$ & $>799$ & \\
\hline DMO & $N$ & 104 & 109 & 83 & \\
\hline Da coluna & Média & 1,18 & 1,15 & 1,19 & $0,323^{*}$ \\
\hline \multirow[t]{4}{*}{ Lombar } & IC (média) & $1,15-1,21$ & $1,11-1,19$ & $1,16-1,22$ & \\
\hline & $D P$ & 0,18 & 0,19 & 0,21 & \\
\hline & Min-max & $0,71-1,84$ & $0,73-1,76$ & $0,74-1,99$ & \\
\hline & Mediana & 1,16 & 1,15 & 1,19 & \\
\hline DMO & $N$ & 104 & 109 & 83 & \\
\hline Do colo & Média & 0,91 & 0,92 & 0,92 & $0,643^{*}$ \\
\hline \multirow[t]{4}{*}{ do fêmur } & IC (média) & $0,88-0,94$ & $0,89-0,95$ & $0,89-0,95$ & \\
\hline & DP & 0,14 & 0,16 & 0,14 & \\
\hline & Min-max & $0,63-1,34$ & $0,54-1,39$ & $0,63-1,30$ & \\
\hline & Mediana & 0,92 & 0,91 & 0,94 & \\
\hline Cálcio & $N$ & 104 & 109 & 83 & \\
\hline corporal & Média & 1016,25 & 1047,96 & 1056,31 & $0,198^{*}$ \\
\hline \multirow[t]{4}{*}{ total } & IC (média) & $985,39-1047,11$ & $1014,76-1081,16$ & $1021,90-1090,72$ & \\
\hline & DP & 158,97 & 175,04 & 156,73 & \\
\hline & Min-max & $643,00-1396,00$ & $514,00-1658,00$ & $682,00-1485,00$ & \\
\hline & Mediana & 1017,00 & 1057,00 & 1059,00 & \\
\hline
\end{tabular}

p: nivel descritivo do teste $t$ - Student

Também avaliou-se as diferenças de médias da DMO no colo do fêmur e na coluna lombar e do conteúdo de cálcio corporal total nos dois grupos de CCD pregresso. Esses grupos foram definidos conforme adequação 
do consumo de cálcio, ou seja, em inadequado e adequado. A tabela 7 apresenta os resultados desta análise.

Tabela 7: Diferenças de médias, desvios padrão, valores mínimos e máximos e mediana dos valores da densitometria óssea nos dois grupos segundo classificação por adequação do CCD pregresso. Hospital Heliópolis. São Paulo, 1997.

\begin{tabular}{|c|c|c|c|c|c|c|c|c|c|c|}
\hline \multirow{3}{*}{$\begin{array}{c}\text { Caracte- } \\
\text { rística }\end{array}$} & \multirow{3}{*}{$\begin{array}{l}\text { Pará- } \\
\text { metro }\end{array}$} & \multicolumn{9}{|c|}{ Consumo de cálcio dietético no passado* } \\
\hline & & \multicolumn{3}{|c|}{$10-20$ anos } & \multicolumn{3}{|c|}{$21-30$ anos } & \multicolumn{3}{|c|}{$31-49$ anos } \\
\hline & & Ade & Ind & $P$ & Ade & Ind & $p$ & Ade & Ind & $p$ \\
\hline DMO da & $N$ & 186 & 101 & & 182 & 107 & & 188 & 93 & \\
\hline coluna & Média & 1,17 & 1,16 & 0,928 & 1,17 & 1,12 & 0,915 & 1,17 & 1,17 & 0,853 \\
\hline \multirow[t]{5}{*}{ lombar } & IC(média) & $1,14,1,20$ & 1,$12 ; 1,20$ & & 1,$14 ; 1,20$ & 1,$20 ; 1,16$ & & 1,$14 ; 1,20$ & 1,$13 ; 1,21$ & \\
\hline & DP & 0,19 & 0,21 & & 0,19 & 0,20 & & 0,19 & 0,20 & \\
\hline & Min & 0,73 & 0,71 & & 0,73 & 0,71 & & 0,73 & 0,71 & \\
\hline & $\operatorname{Max}$ & 1,76 & 1,99 & & 1,76 & 1,99 & & 1,99 & 1,84 & \\
\hline & Mediana & 1,18 & 1,15 & & 1,19 & 1,15 & & 1,18 & 1,15 & \\
\hline DMO do & $N$ & 186 & 101 & & 182 & 107 & & 188 & 93 & \\
\hline colo do & Média & 0,92 & 0,91 & 0,759 & 0,93 & 0,90 & 0,167 & 0,93 & 0,90 & 0,205 \\
\hline \multirow[t]{5}{*}{ fêmur } & IC(média) & 0,$90 ; 0,94$ & 0,$88 ; 0,94$ & & 0,$91 ; 0,95$ & 0,$87 ; 0,93$ & & $0,91,0,95$ & 0,$87 ; 0,93$ & \\
\hline & DP & 0,15 & 0,15 & & 0,15 & 0,13 & & 0,15 & 0,14 & \\
\hline & Min & 0,54 & 0,63 & & 0,54 & 0,63 & & 0,57 & 0,63 & \\
\hline & Max & 1,39 & 1,34 & & 1,39 & 1,28 & & 1,16 & 1,30 & \\
\hline & Mediana & 0,93 & 0,91 & & 0,93 & 0,89 & & 0,90 & 0,91 & \\
\hline Cálcio & $N$ & 186 & 101 & & 182 & 107 & & 188 & 93 & \\
\hline Corporal & Média & 1057,18 & 1003,82 & 0,013 & 1049,88 & 1014,01 & 0,044 & 1048,19 & 1017,18 & 0,285 \\
\hline \multirow[t]{6}{*}{ Total } & IC(média) & $1030,23:$ & 972,41 & & 1025,47 & 983,69 & & 1025,06 & 983,42 & \\
\hline & & 1078,13 & 1035,23 & & 1074,29 & 1044,33 & & 1071,32 & 1050,94 & \\
\hline & DP & 166,65 & 159,44 & & 168,00 & 158,32 & & 161,78 & 164,37 & \\
\hline & Min & 514,00 & 682,00 & & 514,00 & 682,00 & & 581,00 & 635,00 & \\
\hline & Max & 1658,00 & 1485,00 & & 1658,00 & 1417,00 & & 1658,00 & 1485,00 & \\
\hline & Mediana & 1054,50 & 1014,00 & & 1044,00 & 1028,00 & & 1042,50 & 1028,00 & \\
\hline
\end{tabular}


Para avaliação da diferença de médias dos dados da densitometria nos grupos conforme adequação do CCD no passado, foram excluídos os participantes que tiveram seu consumo ignorado. Fez-se esta opção para garantia do teste de diferença de médias. $O$ número de participantes nesta situação foi extremamente inferior aos grupos com consumo adequado e inadequado, como já demonstrado na tabela 3.

Não houve diferença estatisticamente significativa entre as médias de DMO na coluna lombar de acordo com adequação do CCD nas idades de 10 a 20 anos $(p=0,928), 21$ a 30 anos $(p=0,915)$ e 31 a 49 anos $(p=0,853)$. 0 mesmo observou-se em relação às médias de DMO no colo do fêmur de acordo com adequação do CCD nas idades de 10 a 20 anos $(p=0,759), 21$ a 30 anos $(p=0,167)$ e 31 a 49 anos $(p=0,205)$.

Comparando-se as médias do conteúdo de cálcio corporal total nos grupos de CCD pregresso, também não se observou relação entre as variáveis na faixa etária de 31 a 49 anos $(p=0,285)$. Contudo houve diferença das médias do conteúdo de cálcio corporal total nas idades de 10 a 20 anos $(p=0,013), 21$ a 30 anos $(p=0,044)$. 
5 - DISCUSSÃO 
Neste estudo, avaliou-se a relação entre o consumo de cálcio dietético e a densidade mineral óssea em 296 homens com 50 anos e mais. Considerando a metodologia utilizada e o tamanho da amostra, não se trata de um estudo representativo da população residente na área de abrangência do Hospital Heliópolis. Contudo, é uma das primeiras pesquisas realizadas no Brasil, sobre a densidade mineral óssea em homens e sua relação com aspectos nutricionais .

A idade média da população foi de 62,5 anos (DP=7,9 anos), e houve predomínio de individuos entre 50 e 69 anos. Este fato coincide com os dados demográficos atuais referentes à população idosa no Brasil, que se expressa com um aumento da população conhecida como "idoso jovem" (Camargo e Saad 1990). Ferreira (1983) considera que entre os 60 e 75 anos se desenvolvam os processos da pré-velhice, dos 75 aos 85 anos, se estabelece a fase da velhice ativa, e que, depois desta idade, evolui a fase da senilidade.

Das características demográficas da população estudada, também, destaca-se o baixo nível de escolaridade, sendo que $73,3 \%$ estudaram só até o $1^{\circ}$ grau e, ainda, sem completá-lo. Comparando-se com estudo de Fornés (1998) em amostra representativa da população adulta residente no Município de Cotia, que encontrou $49,3 \%$ da população masculina com nível de escolaridade até $\circ 1^{\circ}$ grau incompleto, observa-se que a população aqui investigada apresentou menor grau de instrução em termos percentuais..

Contudo, considerando dados do censo demográfico de 1991 (Fundação SEADE 1994; Fundação IBGE 1996), é possível afirmar que o perfil educacional da população estudada se aproxima da realidade educacional brasileira e paulista. A taxa de alfabetização do Estado de São Paulo em 1991 na população urbana com 60 anos e mais era de $83 \%$, e na região metropolitana de São Paulo de $76,3 \%$. O número médio de séries escolares completas nos brasileiros com 50 anos e mais, residentes nas regiōes urbanas em 1990, é de 3,6 séries. Dado muito próximo ao do Brasil foi observado no Estado de São Paulo: 3,8 séries. 
Em relação à avaliação do consumo de cálcio dietético, constatou-se que a maioria da população $(72 \%)$ apresentou consumo de cálcio dietético (CCD) atual abaixo da recomendação do NRC/89, com média de 696,2 mg/dia. Houve uma importante variação do $C C D$ atual no grupo. Obteve-se desvio padrão da média de CCD atual de $333,8 \mathrm{mg}$, e valores máximo e mínimo de 118,7 e $2288,6 \mathrm{mg}$ de cálcio, respectivamente.

Vários autores (Allen 1986; Arnauld e Sanchez 1990; Borelli 1994; Lindsay 1995; NIH 1994) recomendam um consumo de cálcio de 1000 a 1500 $\mathrm{mg} / \mathrm{dia}$. Contemplando essas novas recomendaçōes e tomando-se como adequado um consumo entre 800 e $1500 \mathrm{mg} / \mathrm{dia}$, observou-se que $72,0 \%$ dos participantes apresentavam consumo deficiente e apenas 8 pacientes $(2,7 \%)$ tiveram um consumo excedente de cálcio (>1500 mg/dia). O NIH (1994) apresenta que os riscos à saúde associados ao alto consumo de cálcio são observados com quantidade muito acima do que é consumida em todo o mundo. $O$ consumo de cálcio menor do que $4 \mathrm{~g} /$ dia é tido como absolutamente seguro por este órgão norte-americano. Na população aqui estudada não foi observado consumo de cálcio no nível tóxico ao organismo humano.

Park e col. (1997), em artigo que aponta considerações e problemas na avaliação dos niveis de consumo atual de cálcio nos Estados Unidos da América, observaram que o $C C D$ dos homens adultos foi muito próximo à recomendação do NRC/1989 (80-95\% da recomendação). Contudo, esses autores chamam a atenção para o fato de que na avaliação da adequação do consumo de nutrientes, não apenas o cálcio, as pesquisas freqüentemente utilizam valores de média e mediana de consumo, desconsiderando a larga variação que há dentre o grupo. Consideram, assim, que consumo médio isolado não seja suficiente para avaliar a adequação do CCD para populações, sugerindo que uma avaliação mais segura possa ser feita com distribuição por percentis de consumo.

Este tipo de avaliação por percentis de consumo não é, ainda, apresentado nas publicações de inquéritos populacionais de consumo de cálcio investigadas. Por isso, fez-se aqui a opção pela manutenção da avaliação por 
adequação de consumo de acordo com recomendação nutricional, de forma a propiciar a comparação de nossos dados com os de outros autores.

A média de CCD atual $(696,2 \mathrm{mg} / \mathrm{dia})$ encontrada no presente estudo não é discrepante do que pode ser observado na literatura. A tabela 8 apresenta resultados de pesquisas que também investigaram o CCD de forma quantitativa. Observa-se que existe grande variação da média de CCD entre as pesquisas aqui apresentadas, além de que são poucos os estudos realizados com a população masculina isoladamente.

Tabela 8: Resultados de estudos de consumo de cálcio dietético:

\begin{tabular}{|c|c|c|c|c|}
\hline $\begin{array}{c}\text { Autor, } \\
\text { Ano }\end{array}$ & País & População & $\begin{array}{l}\text { ldade } \\
\text { (anos) }\end{array}$ & $\begin{array}{c}\text { CCD médio } \\
\text { ( } \mathrm{mg} / \mathrm{dia})\end{array}$ \\
\hline Sampaio 1997 & Brasil & $\begin{array}{c}\text { Mulheres e } \\
\text { Homens }\end{array}$ & $68(60-88)$ & $\begin{array}{l}455 \\
505\end{array}$ \\
\hline $\begin{array}{l}\text { HANES II (Heaney e col. } \\
\text { 1982) }\end{array}$ & USA & $\begin{array}{l}\text { Mulheres } \\
\text { Homens }\end{array}$ & $65 e+$ & $\begin{array}{l}475 \\
597\end{array}$ \\
\hline $\begin{array}{l}\text { HANES I (Heaney e col. } \\
\text { 1982) }\end{array}$ & USA & $\begin{array}{l}\text { Mulheres } \\
\text { Homens }\end{array}$ & $65 e+$ & $\begin{array}{l}495 \\
602\end{array}$ \\
\hline Nguyen e col. 1994 & Australia & $\begin{array}{c}\text { Mulheres } \\
\text { Homens }\end{array}$ & $\begin{array}{l}69(\mathrm{DP}=0,2) \\
69(\mathrm{DP}=0,2)\end{array}$ & $\begin{array}{l}630 \\
630\end{array}$ \\
\hline Nguyen e col. 1996 & Australia & Homens & $60 e+$ & 646 \\
\hline Sandler e col. 1985 & USA & Mulheres & $57(\mathrm{DP}=8,6)$ & 720 \\
\hline Fleming e col. 1994 & USA & $\begin{array}{l}\text { Mulheres } \\
\text { Homens }\end{array}$ & $1-70 e+$ & 737 \\
\hline $\begin{array}{l}\text { Krall e Dawson-Hugles } \\
1993\end{array}$ & USA & $\begin{array}{c}\text { Mulheres e } \\
\text { Homens }\end{array}$ & $\begin{array}{l}60(\mathrm{DP}=6) \\
63(\mathrm{DP}=6)\end{array}$ & $\begin{array}{l}740 \\
852\end{array}$ \\
\hline Rodríguez e col. 1998 & Chile & Mulheres & $57(\mathrm{DP}=1,5)$ & 745 \\
\hline Angus e col. 1988 & Australia & Mulheres & $23-75$ & $785 / 696$ \\
\hline Gamez e col. 1997 & Espanha & $\begin{array}{c}\text { Mulheres e } \\
\text { Homens }\end{array}$ & $60-97$ & 990 \\
\hline Wang e col. 1997 & México & Mulheres & $59-84$ & 1020 \\
\hline
\end{tabular}


Dentre as pesquisas citadas na tabela 8 , a de Sampaio (1997) foi realizada com idosos brasileiros residentes no município de São Paulo, com idade média de 68 anos, e o total de homens investigados foi 98 . O consumo de cálcio foi mensurado com utilização do método "recordatório de 24 horas", e os homens investigados tiveram consumo médio de cálcio (505 mg/dia) inferior ao encontrado em nossa população (696 mg/dia).

Observa-se que apenas três dos estudos apresentados na tabela 8 , Krall e Dawson-Hugles 1993, Gamez e col. 1997, Wang e col. 1997, tiveram média de consumo de cálcio superior a $800 \mathrm{mg} / \mathrm{dia}$. Sendo que destes, somente o estudo mexicano não investigou o consumo em homens.

O nosso estudo confirma as conclusões observadas na literatura sobre a alimentação de idosos, que apontam para uma inadequação em relação aos micronutrientes e em especial ao cálcio (O'Halon e Kohes 1978, Elsborg 1983, Marucci 1992, Constants e col. 1994, Najas e col. 1994, Frank 1996) .

A avaliação do CCD atual também foi feita pela distribuição da população em três grupos de consumo segundo alcance da recomendação do NRC (1989) para cálcio. Da população estudada, 35,5\% não alcançaram nem ao menos $2 / 3$ da recomendação, o que corresponderia a um consumo inferior a $533 \mathrm{mg}$ de cálcio por dia.

Alguns autores têm adotado $o$ ponto de corte de $2 / 3$ da recomendação para avaliar a adequação da dieta em relação aos nutrientes (Vir e Love 1978, O'Hanlon e col. 1978, Sahyoun e col. 1988, Ryan e col. 1992, Stevens e col. 1992, Sampaio 1997). Os estudos de balanço metabólico do cálcio têm apresentado valores médios de necessidade deste nutriente de cerca de 500-600 mg por dia (Heaney e col. 1982, Nordin e col. 1987, Nordin e Morris 1989, Heaney 1992, Nordin 1997b). Considerando estes aspectos, observa-se que $35,5 \%$ da população no presente estudo, referente à parcela que não alcançou ao menos $2 / 3$ da recomendação, pode apresentar balanço 
negativo de cálcio. Contudo, esta afirmação só poderia ser comprovada com a realização de estudos metabólicos.

Em relação ao CCD pregresso, aproximadamente $60 \%$ da população apresentou adequação no consumo e $35 \%$ inadequação. Esses dados diferem bastante dos dados do CCD atual, que esteve inadequado em $72 \%$ da população. As diferenças entre esses dois períodos de investigação do consumo, atual e pregresso, não se limitam aos resultados da adequação, mas, sim, iniciam nas formas de avaliação e adequação do consumo, o que dificulta comparações e tomada de conclusões em relação à evolução do consumo de cálcio ao longo da vida. Para o consumo atual, foi feita uma avaliação quantitativa em comparação à recomendação do NRC/89. Já para o consumo pregresso, a avaliação partiu do questionário de freqüência de leite e seus substitutos, e considerou-se adequado o consumo diário de cálcio e inadequado nas outras freqüências de consumo, para o periodo correspondente.

Estudo de Fleming e Heimbach (1994) avaliou o consumo de cálcio nos Estados Unidos da América. Foram utilizados os mesmos métodos de inquérito alimentar, recordatório de $\mathbf{2 4}$ horas associado ao diário alimentar de 2 dias, em todas as faixas etárias estudadas. Esses autores observaram para homens consumo médio de cálcio de $845 \mathrm{mg} /$ dia na faixa etária de 30-39 anos, $681 \mathrm{mg} / \mathrm{dia}$ entre $40-49$ anos, $706 \mathrm{mg} / \mathrm{dia}$ entre $50-59$ anos, $713 \mathrm{mg} / \mathrm{dia}$ entre $60-69$ anos e $713 \mathrm{mg} / \mathrm{dia}$ nos indivíduos com 70 anos e mais.

Frequentemente é salientado as limitações de avaliação de consumo de forma retrospectiva, que pode ter grande interferência da memória do entrevistado e dúvidas em relação à veracidade da informação. Apesar de que na nossa população, o número de individuos que não souberam referir o seu consumo pregresso de alimentos fontes de cálcio, foi bastante reduzido (máximo de $5 \%$ na faixa etária de 31 a 49 anos, tabela 3). Uma possivel hipótese que possa justificar esta observação, talvez seja a forma de distribuição do cálcio nos alimentos. As principais fontes alimentares de cálcio são os leites e seus derivados: queijo, iogurte, coalhada, requeijão; exceto 
manteiga e creme de leite. (IBGE 1977; Franco 1992; Philippi e col. 1996; Pinheiro e col. 1996). Esses alimentos compõem habitualmente o cardápio de refeiçōes como o desjejum e ceia, o que pode favorecer a lembrança do entrevistado.

No presente estudo, no que tange às fontes de cálcio dietético consumidas, o leite, os produtos e as preparações lácteos foram consideradas as principais fontes de cálcio, correspondendo a $93,7 \%$ na distribuição percentual por freqüência de consumo. $O$ grupo dos leites foi o mais consumido dentre as fontes de cálcio, $62,8 \%$.

Resultados semelhantes foram observados por Angus e col. (1988), que avaliando as fontes de cálcio na dieta de mulheres australianas na pósmenopausa, observaram que os produtos lácteos constituíram as principais fontes de cálcio, sendo que leite e queijos ofereceram $57 \%$ do cálcio consumido. Também Fleming e Heimbach (1994) na avaliação da dieta nos Estados Unidos da América, verificaram que leites, produtos lácteos e preparações que tinham como ingrediente o leite ofereceram $72 \%$ do total de cálcio consumido.

Vários autores indicam que o cálcio contido no leite e produtos lácteos é melhor absorvido que em outros alimentos, como nos vegetais folhosos ( Heaney e col. 1982, Heaney e col. 1990, Weaver 1992, Fujita 1997). Desta forma, como o cálcio na dieta da população aqui estudada foi ofertado principalmente pelos produtos e preparações lácteas, pode-se dizer que há um bom aproveitamento do nutriente. Já o grupo das hortaliças teve uma baixa freqüência de consumo, correspondendo apenas a $2,6 \%$ das fontes de cálcio consumida. Os alimentos do grupo das hortaliças que foram considerados fontes de cálcio (agriāo, espinafre, couve, bertalha, mostarda e brócolis), podem apresentar taxas de absorção menores quando comparado ao cálcio do leite. A taxa de absorção do leite pode chegar a $40 \%$ contra $5 \%$ do espinafre (Heaney e col. 1990). Excluindo o aspecto da biodisponibilidade e absorção do cálcio nas hortaliças, não é possivel considerá-las uma importante fonte de cálcio na população estudada pela baixa freqüência de consumo. 
Em relação à densidade mineral óssea (DMO), encontrou-se médias para coluna lombar de $1,169 \mathrm{~g} / \mathrm{cm}^{2}$ e para colo do fêmur de $0,917 \mathrm{~g} / \mathrm{cm}^{2}$. Comparando os valores das medidas ósseas obtidos no presente trabalho aos apresentados em estudo com a população masculina norte-americana (Looker e col. 1997), observa-se valores menores tanto para a coluna lombar quanto para o colo do fêmur na população brasileira. No estudo de Nguyen e col. (1996) com homens idosos na Austrália, na faixa etária de 60-64 anos, os valores médios obtidos para DMO no colo do fêmur foi $0,94 \mathrm{~g} / \mathrm{cm}^{2}$ e para DMO da coluna lombar foi $1,23 \mathrm{~g} / \mathrm{cm}^{2}$, na faixa etária de $60-64$ anos. Esses valores também são maiores do que os obtidos com os homens brasileiros. Contudo, foram superiores os valores das medidas ósseas obtidos no nosso estudo em relação aos apresentados por Glynn e col. (1995) para DMO do colo do fêmur $\left(0,78 \mathrm{~g} / \mathrm{cm}^{2}\right)$ em população composta por homens também com 50 anos e mais.

A média de conteúdo de cálcio corporal total encontrada foi de 1039 g, com variação de 514 a 1658 g. Como mencionado por Nordin (1997a) a principal função do cálcio no corpo é promover rigidez no esqueleto, correspondendo a $25 \%$ do peso seco do osso. Segundo Odell e Heath (1993) $90 \%$ do cálcio corporal total está presente na forma de hidroxiapatita no osso $\left[\mathrm{Ca}_{10}(\mathrm{OH})_{2}\left(\mathrm{PO}_{4}\right)_{6}\right]$. A matriz mineral óssea é composta, principalmente, por hidroxiapatita e por alguns sais incorporados (sais de $\mathrm{Na}, \mathrm{K}, \mathrm{Mg}$, citrato e carbonato).

Nordin e Polley (1987a) referem que no esqueleto há, aproximadamente, $1200 \mathrm{~g}$ de cálcio. Ao tomar este valor como referencial, observa-se que o valor da média de conteúdo de cálcio corporal total encontrado (1039 g) foi menor na população estudada. Quando estende-se esta comparação para os valores mínimo e máximo $(514$ - $1658 \mathrm{~g})$ do conteúdo de cálcio corporal total, pode-se notar que alguns participantes tiveram grande distanciamento do conteúdo de cálcio no esqueleto tido como ideal. Como o cálcio é um importante constituinte da matriz mineral óssea, possivelmente, esses indivíduos com valores menores podem apresentar maior fragilidade óssea. 
Ao se correlacionar o CCD atual com os dados de DMO no colo do fêmur e da coluna lombar não se observou nenhuma correlação entre as variáveis. Distribuindo a população nos grupos segundo alcance da recomendação de cálcio do NRC/89 pelo CCD atual, também não se observou relações entre DMO e CCD atual. Não houve diferenças estatísticamente significativa na DMO nos grupos de maior (>799 mg/dia), intermediário (533 a $799 \mathrm{mg} / \mathrm{dia}$ ) e menor ( $<533 \mathrm{mg} / \mathrm{dia}$ ) consumo de cálcio. Algumas pesquisas não corroboram os resultados aqui obtidos. Em estudo de Nguyen e col. (1996) com homens com 60 anos e mais, o maior consumo de cálcio foi associado com maior DMO tanto para coluna, como para o quadril. Glynn e col. (1995), em estudo com homens idosos, referem ter encontrado pequena associação entre consumo de cálcio dietético corrente e DMO do colo do fêmur. Outro estudo de Nguyen e col. (1994) com mulheres e homens idosos, apresentou correlação positiva independente entre o consumo de cálcio dietético e DMO no colo do fêmur e na coluna lombar para homens, mas em mulheres esse efeito somente foi observado no colo do fêmur. Kelly e col. (1990) em estudo que avaliou os fatores determinantes da densidade mineral óssea em homens adultos e idosos normais, observaram uma forte correlação positiva entre consumo de cálcio dietético e DMO na coluna lombar e colo do fêmur.

Por outro lado, em estudo de Rodríguez e Novik (1998) sobre ingestão de cálcio e DMO em mulheres na menopausa desenvolvido no Chile, não se observou correlação entre o consumo de cálcio e a DMO na coluna lombar e colo do fêmur. Sandler e col. (1985) não encontraram correlação significante entre o consumo de cálcio atual e DMO do rádio. Também em estudo de Cumming e col. (1997) sobre consumo de cálcio e risco de fratura, não houve importante associação entre consumo de cálcio dietético e risco de fraturas de quadril, de úmero proximal, vertebral e outras fraturas não vertebrais.

Em nosso estudo, houve correlação positiva entre o conteúdo de cálcio corporal total e CCD atual $(p=0,047)$. Esta foi a única correlação obtida em relação ao consumo atual. Apesar deste resultado, contrariamente não houve diferenças estatísticamente significativas do conteúdo de cálcio corporal 
total nos grupos de maior, intermediário e menor consumo atual de cálcio. Não foi possivel comparar esses resultados com dados de literatura, uma vez que em nenhum dos trabalhos científicos encontrados, houve a apresentação do valor de conteúdo de cálcio corporal total, de sua provável relação com medidas ósseas ou com o consumo de cálcio dietético ou medicamentoso.

Em relação ao CCD pregresso não foi possivel identificar relação com os dados de densidade mineral óssea. Os valores médios de DMO na coluna lombar e colo do fêmur foram estatisticamente diferentes de acordo com a adequação do CCD no passado. Avaliar o consumo de cálcio no passado é importante por que o adequado CCD maximiza o pico de massa óssea que ocorre na adolescência e se completa na terceira década de vida (NHI 1994, Branca 1997). Apesar disto são poucos os estudos que fizeram uma avaliação do CCD no passado e suas relações com a DMO na maturidade e envelhecimento.

Sandler e col. (1985) observaram DMO significativamente maior em mulheres na pós-menopausa que referiram consumir sempre leite junto às refeições, quando comparado às mulheres que referiram consumir leite às vezes ou nunca junto às refeições.

À semelhança da correlação encontrada entre o conteúdo de cálcio corporal total e o CCD atual, também observou-se relações entre esta variável da densitometria óssea e o CCD pregresso. Constatou-se que houve diferenças das médias do conteúdo de cálcio corporal total nas idades de 10 a 20 anos $(p=0,013), 21$ a 30 anos $(p=0,044)$. Como mencionado anteriormente, não foi possivel comparar esses resultados com os da literatura, pela inexistência de pesquisas científicas que tenham abordado a varíavel conteúdo de cálcio corporal total.

De qualquer forma, algumas considerações podem ser desenvolvidas pela apreciação das funções do cálcio no organismo. O cálcio é um mineral essencial na alimentação humana, e a sua necessidade é largamente determinada pelas necessidades esqueléticas. A quantidade de 
osso que pode ser acumulada é limitada pela quantidade de cálcio ingerida, uma vez que o cálcio é o mais abundante mineral no osso. Os impactos positivos do aumento do consumo de cálcio dietético sobre a massa óssea, que apresenta aumento associado, têm sido descritos na infância (Johnston e col. 1992), na adolescência (Recker e col. 1992) e na fase do adulto jovem (Matkovic 1991). No presente estudo, pudemos verificar que os grupos de indivíduos que tiveram $C C D$ pregresso adequado no período de pico de massa óssea (10 a 20 anos e 21 a 30 anos), apresentaram valores médios de conteúdo de cálcio corporal total no presente significativamente maiores do que os grupos de CCD pregresso considerados inadequados. Isto significa que esses indivíduos de maior consumo de cálcio, podem ter retido mais cálcio ao organismo e, consequentemente, ao osso. Contudo, não foi possível observar as relações deste maior acúmulo de cálcio sobre à DMO.

Conforme apresentado por Nguyen e col. (1994) o papel do cálcio dietético sobre a massa esquelética permanece controverso, e sua interação com outros fatores determinantes podem confundir na análise independente do efeito de cada um desses fatores sobre a DMO.

No presente estudo optou-se por um corte transversal, que teve como objetivo avaliar somente duas variáveis principais (DMO e CCD) e não apresenta uma análise mais extensa e profunda de outros fatores que podem estar interferindo na DMO. A massa óssea apresenta caráter multifatorial e existem outros fatores determinantes além do cálcio como a genética, a história médica e outros fatores dietéticos e ambientais, como o consumo de proteínas e calorias, nivel de vitamina $\mathrm{D}$, composição corporal e grau de atividade física. O tamanho da população estudada, $n=296$, também pode não ter sido o suficiente para garantir o teste de correlação, uma vez que os valores de $r$ foram baixos. Talvez com uma população de estudo ampliada, as correlações poderiam ter sido mais positivas. 
6 - CONCLUSÕES 
Do presente estudo sobre as relações do consumo de cálcio dietético e densidade mineral óssea em homens adultos e idosos, conclui-se que na população estudada:

- O consumo de cálcio dietético atual apresentou-se inadequado para a maioria da população.

- O consumo de cálcio dietético pregresso foi considerado adequado para maioria da população.

- A principal fonte de cálcio dietético consumida foi o leite, seguido dos derivados lácteos.

- Não houve correlação estatisticamente significativa entre o consumo de cálcio dietético e a densidade mineral óssea na coluna lombar e colo do fêmur.

- Houve correlação estatisticamente significativa entre o consumo de cálcio dietético atual e o conteúdo de cálcio corporal total.

- Os valores médios da DMO na coluna lombar e no colo do fêmur, e de conteúdo de cálcio corporal total não tiveram diferenças estatisticamente significativas nos três grupos de CCD atual conforme alcance da recomendação dietética para cálcio.

- Os valores médios da DMO na coluna lombar e no colo do fêmur não tiveram diferenças estatisticamente significativas nos dois grupos de CCD pregresso conforme adequação da dieta.

- Os valores médios do conteúdo de cálcio corporal total apresentaram diferenças estatisticamente significativas nos dois grupos de CCD pregresso conforme adequação da dieta, nas idades de 10-20 anos e 2130 anos. Contudo, o mesmo não se observou nas idades de 31-49 anos. 


\section{7 - RECOMENDAÇÕES}


Ao final do presente estudo, considerando suas descobertas, dificuldades, limitações, erros e acertos, podem ser apresentadas algumas recomendações de temas a serem desenvolvidos em futuras pesquisas:

- Estudos prospectivos e representativos da população brasileira, para melhor elucidar a epidemiologia da osteoporose no país.

- Estudos prospectivos para determinar como o cálcio e outros fatores dietéticos e ambientais podem agir e interagir na determinação da massa óssea. Essas futuras pesquisas tornarão possível a adoção de medidas preventivas de caráter nutricional, em nivel populacional e de intervenção individual, visando evitar a osteoporose e as fraturas dela decorrentes.

- Estudos sobre metodologia segura de colheita dos dados para investigar o consumo de alimentos, em especial fontes de alguns nutrientes como vitaminas e minerais, de forma prospectiva e retrospectiva.

- Definição de padrões mais seguros para a avaliação do consumo e da sua adequação. Quanto mais precisa a informação dietética, maior será a segurança dos pesquisadores que investigam as relações entre nutrição e doenças crônicas, a exemplo da osteoporose. 
8- REFERÊNCIAS BIBLIOGRÁFICAS 
1. Allen LH. Calcium and osteoporosis. Nutrition Today 1986; may/june,6-10.

2. Angus RM, Pocock NA, Eisman JA. Nutritional intake of pre- and postmenopausal Australian women with special reference to calcium. Eur $J$ Clin Nutr 1988; 42: 617-625.

3. Arnaud CD, Sanchez SD. The role of calcium in osteoporosis. Annu Rev Nutr 1990; 10: 397-414.

4. Berquó ES, Leite VM. Algumas considerações sobre a demografia da população idosa no Brasil. Ciênc Cult 1988; 40(7): 679-88.

5. Bing FC, Brennemann J, Fishbein M, Lewis HB, Powers GF, McLester JS et. al. Council on foods. J A M A 1937; 108 (22): 1890-1.

6. Borelli A. Envelhecimento ósseo: osteoporose. In: Carvalho Filho ET, Papaléo Netto M. Geriatria: fundamentos, clínica e terapêutica. São Paulo: Atheneu; 1994. p.298-307.

7. Branca F. Calcium, micronutrients and physical activity to maximize bone mass during growth. FAO: Food, Nutrition and Agriculture 1997; 20: 44-49.

8. Camargo ABM, Saad PM. A transição demográfica no Brasil e seu impacto na estrutura etária da população. In: Fundação SEADE. O idoso na Grande São Paulo. São Paulo, 1990. p.9-25. (Coleção Realidade Paulista).

9. Cappuccio FP, Elliot P, Allender PS, Pryer J, Follman DA, Cutler JA. Epidemiologic association between dietary calcium intake and blood pressure: a meta-analysis of published data. Am J Epidemiol 1995; 142 (9): 935-45.

10. Chapman KM, Chan MW, Clark CD. Factors influencing dairy calcium intake in women. J Am Coll Nutr 1995; 14 (4): 336-40. 
11. Chapuy MC, Arlot ME, Dubouef F, Brun J, Crouzet B, Arnaud S et. al. Vitamin $D_{3}$ and calcium to prevent hip fractures in elderly women. $N$ Engl $J$ Med 1992; 327(23): 1637-42.

12. Charles P. Calcium absorption and calcium bioavailability. Journal of Internal Medicine 1992; 231: 161-168.

13. Consensus Development Conference: Diagnosis, prophylaxis and treatment of osteoporosis. Internacional Symposium on Osteoporosis, 1993. Conference Report. Am J Med 1993; 94: 646-50.

14. Consensus Development Statement: Who are candidates for prevention and treatment for osteoporosis? Osteoporosis Int 1997; 7: 1-6.

15. Constants T, Delarue J, Rivol M, Theret V, Lamisse F. Effects of nutrition education on calcium intake in the elderly. J Amer Diet Assoc 1994; 94 : 447-8.

16. Cooper C, Barker DJP, Wickham C. Physical activity, muscle strength and calcium intake in fracture of the proximal femur in Britain. $\mathrm{Br}$ Med $\mathrm{J}$ 1988; 297: $1443-6$.

17. Cooper $\mathrm{C}$. The problem: health impact of osteoporosis. Scand J Rheumatol 1996; 25 (Suppl103): 3-5.

18. Cruz JAA, Varela OM, Staveren WA, Trichopoulou A, Roszkowski W. Intake of vitamins and minerals. Eur J Clin Nutr 1991; 45: 121-38.

19. Cumming RG, Cummings SR, Nevitt MC, Scott J, Ensrud KE, Vogt TM, Fox $\mathrm{K}$. Calcium intake and fracture risk: results from the study of osteoporotic fractures. Am J Epidemiol 1997; 145 (10): 926-34.

20. Cummings SR, Kelsey JL, Newitt MC, O'Dowd. Epidemiology of osteoporotic fractures. Epidemiol Rev 1985; 7: 178-208. 
21. Cummings SR, Black DM, Rubin SM. Lifetime risks on hip, Colles or vertebral fracture and coronary heart disease among white postmenopausal women. Arch Intern Med 1989; 149: 2445-8.

22. Curiati JAE, Alencar YMG de. Nutrição e Envelhecimento. In: Carvalho Filho ET, Papaléo Netto M. Geriatria: fundamentos, clínica e terapêutica. São Paulo: Atheneu, 1994. p.335-44.

23. Czajka-Narins DM. Minerais. In: Mahan LK; Escott-Stump S. Krause: alimentos, nutrição e dietoterapia. São Paulo: Roca, 1998. p. 123-66.

24. Dawson-Hugles B. Calcium and vitamin D metabolism and nutritional status in the elderly. In: Rosenberg IH. Nutritional assessment of elderly populations: measure and function. New York: Raven Press, 1995. p.25264.

25. Dawson-Hugles B, Jacques $P$, Shipp $C$. Dietary calcium intake and bone loss from the spine in healthy postmenopausal womem. Am J Clin Nutr 1987; 46: 685-7.

26. Dequeker J, Ranstam J, Valsson J, Sigurgevisson B, Allander E, MEDOS Study Group. The mediterranean osteoporosis (MEDOS) study questionnaire. Clinical Rheumatology 1991; 10 (1): 54-72.

27. Dwyer JT. Assessment of dietary intake. In: Shils ME, Young VR. Modern nutrition in Health and disease. Philadelphia: Lea \& Febiger, 1988. p.887905.

28. Elffors L, Allander E, Kanis JA. The variable incidence of hip fractures in Southern Europe. Osteoporos Int 1994; 4: 253-63.

29. Elsborg L. The intake of vitamins and minerals by the elderly at home. Internat J Vit Nutr Res 1983; 53: 321-9. 
30. FAO. Production yearbook 1990. Rome, 1991, 44 citado por Nordin BEC. Calcium in health and disease. FAO: Food, Nutrition and Agriculture 1997a; 20: 13-26.

31. Ferreira FAG. Nutrição Humana. Lisboa: Fundação Calouste Gulbenkian; 1983.

32. Fleming KH, Heimbach JT. Consumption of calcium in the U.S.: food sources and intake levels. J Nutr 1994; 124(8 suppl): 1426-30.

33. Fornés NAS. Padrões alimentares e suas relações com os lipídios séricos em população da área metropolitana de São Paulo. São Paulo, 1998. [Tese de doutorado - Faculdade de Saúde Pública - USP.]

34. Franco G. Tabela de composição química dos alimentos. São Paulo: Atheneu; 1992.

35. Frank AA. Estudo antropométrico e dietético de idosos. Rio de Janeiro, 1996. [Dissertação de Mestrado - Instituto de Nutrição -UFRJ.]

36. Freudenheim JL, Johnson NE, Smith EL. Relationships between usual nutrient intake and bone-mineral content of womem 35-65 years of age: longitudinal and cross-sectional analysis. Am J Clin Nutr 1986; 44: 863-76.

37. Fujita T. Osteoporosis: past, present and future. Osteoporos Int 1997; 7 (suppl.3): 6-9.

38. Fundação SEADE. Anuário estatístico do Estado de São Paulo: 1993. São Paulo; 1994.

39. Fundação IBGE. Anuário estatístico do Brasil: 1995. Rio de Janeiro; 1996. 
40. Gamez C, Artacho R, Ruiz-Lopez MD, Navarro M, Puerta A, Lopez MC. Serum concentrationa and dietary intake of $\mathrm{Mg}$ and $\mathrm{Ca}$ in institutionalized elderly people. Science of the Total Environment 1997; 203 (3): 245-51.

41. Garland CF, Garland FC, Gorham ED. Can colon cancer incidence and death rates be reduced with calcium nad vitamin D? Am J Clin Nutr 1991; 54: 193-201.

42. Glynn NW, Meilahn E, Charron M, Anderson SJ, Kuller LH, Cauley JA. Determinants of bone mineral density in older men. J Bone Miner Res 1995; 10 (11): 1769-77.

43. Grisso JA, Kelsey JL, O'Brien LA, Milles CG, Sidney S, Maislin G et. al. The Hip Fractures Study Group. Risk factors for hip fracture in men. Am J Epidemiol 1997; 145 (9): 786-93.

44. Gullberg B, Johnell O, Kanis JA. World-wide projections for hip fractures. Osteoporos Int 1997; 7: 407-13.

45. Heaney RP, Gallagher JC, Jonhston CC, Neer R, Parfitt AM, Chir B, Whedon DG. Calcium nutrition and bone health in the elderly. Am J Clin Nutr 1982; 36: 986-1013.

46. Heaney RP, Recker RR, Weaver CM. Absorbability of calcium sources: the limited role of solubility. Calcif Tissue Int 1990; 46: 300-4.

47. Heaney RP. Calcium intake in the osteoporotic fracture context: introduction. Am J Clin Nutr 1991; 54: 242-4.

48. Heaney RP. Calcium in the prevention and treatment of osteoporosis. Journal of Internal Medicine 1992; 231: 169-80. 
49. Heaney RP. The roles of calcium and vitamin $D$ in skeletal health: na evolutionary perspective. FAO: Food, Nutrition and Agriculture 1997; 20: 411.

50. Holbrook TL, Barrett-Connor E, Wingard DL. Dietary intake and risk of hip fracture: 14-years prospective population study. Lancet 1988; 2: 1046-9.

51. Horsman A, Gallagher JC, Simpson M, Nordin BEC. Prospective trial of oestrogen and calcium in postmenopausal women. Br Med J 1977; ii: 78992.

52. Horwath CC, Govan $\mathrm{CH}$, Campbell AJ, Busby W, Scott V. Factors influencing milk and milk product consumption in young and elderly women with low calcium intakes. Nutrition Research 1995; 15 (12): 1735-45.

53. Instituto Brasileiro de Geografia e Estatística (IBGE). Secretaria de Planejamento da Presidência da República. Tabela de composição dos alimentos. Rio de Janeiro;1977.

54. Jacob Filho W, Souza RR de. Anatomia e fisiologia do envelhecimento. In: Carvalho Filho ET, Papaléo Netto M. Geriatria: fundamentos, clínica e terapêutica. São Paulo: Atheneu, 1994. p. $31-40$.

55. Jacobsen SJ, Goldberg J, Miles TP, Brody JÁ, Stiers W, Rimm AA. Hip fractures incidence among the old and very old: a population-based study of 745,435 cases. American Journal of Public Health 1990; 80(7): 871-73.

56. Johnell O, Gullberg B, Allander E, Kanis JA. The apparent incidence of hip fractures in Europe: a study of national register sources. Osteoporosis Int 1992; 2: 298-302.

57. Johnston CC Jr, Miller JZ, Slemenda CW, Reister TK, Hui S, Christian JC, Peacock M. Calcium supplementation and increases in bone mineral density in children. N Engl J Med 1992; 327: 82-7. 
58. Kalache A, Veras RP, Ramos LR. O envelhecimento da população mundial: um desafio novo. Rev Saúde púb/ 1987; 21(3): 200-10.

59. Kanis JA, Passmore R. Calcium supplementation of the diet - II: not justified by present evidence. Br Med J 1989; 298: 205-8.

60. Kanis JA, Pitt FA. Epidemiology of osteoporosis. Bone 1992; 13 (suppl.1): $7-15$.

61. Kanis JA, Melton JIII, Christiansen C, Johnston CC, Khaltaev N. The diagnosis of osteoporosis. J Bone Miner Res 1994; 9 (8): 1137-41.

62. Kelly PJ, Pocock NA, Sambrook PN, Eisman JA. Dietary calcium, Sex hormones, and bone mineral density in men. BMJ 1990; 300: 1361-64.

63. Knekt $P$, Jarvinen $R$, Seppanen R, Pukkala $E$, Aromaa A. Intake of dairy products and the risk of breast cancer. Br J Cancer 1996; 73 (5): 687-91.

64. Krall EA, Dawson-Hugles B. Heritable and life-style determinants of bone mineral density. J Bone Miner Res 1993; 8 (1): 1-9.

65. Lau E, Donnan S, Barker DJP, Cooper C. Physical activity and calcium intake in fracture of the proximal femur in Hong Kong. Br Med J 1988; 297:1441-3.

66. Laurenti R. Transição demográfica e transição epidemiológica. In: Anais do Congresso Brasileiro de Epidemiologia; 1990; Campinas, São Paulo, Brasil. São Paulo: ABRASCO; 1990. p. 143-65.

67. Lindsay R. Vitamin D and Calcium Assessment in the Elderly. In. Rosenberg IH. Nutritional assessment of elderly populations: measure and function. New York: Raven Press; 1995. p.301-3. 
68. Looker AC, Loria CM, Carroll MD, McDowell MA, Johnson $\mathrm{Cl}$. Calcium intake of mexicans americans, cubans, puerto ricans, non-hispanic whites, and non-hispanic blacks in the United States. J Am Diet Assoc 1993; 93: 1274-9.

69. Looker AC, Orwoll ES, Johnston JR, Lindsay RL, Wahner HW, Dunn WL, e col. Prevalence of low femoral bone density in older U.S. adults from NHANES III. J Bone Miner Res 1997; 12 (11): 1761-71.

70. Marucci MFN. Avaliação das dietas oferecidas em instituições para idosos, localizadas no município de São Paulo. São Paulo, 1985. [Dissertação de Mestrado - Faculdade de Saúde Pública -USP.]

71. Marucci MFN. Aspectos nutricionais e hábitos alimentares de idosos, matriculados em ambulatório geriátrico. São Paulo, 1992. [Tese de doutorado - Faculdade de Saúde Pública - USP.]

72. Marucci MFN, Gomes MMBC. Interação droga-nutriente em idosos. In: Papaléo Netto M. Gerontologia. São Paulo: Atheneu; 1997. p.273-83.

73. Matkovic V, Kostial K, Simonovic I, Buzina R, Braderec I, Nordin BEC. Bone status and fracture rates in two regions of Yugoslovia. Am J Clin Nutr 1979; 32: $540-9$.

74. Matkovic V. Calcium metabolism and calcium requirements during skeletal modeling and consolidation of bone mass. Am J Clin Nutr 1991; 54: 245S605 .

75. Mautalen C, Pumarino H. Epidemiology of osteoporosis in South America. Osteoporos Int 1997; 7 (Suppl.3): 73-7.

76. McCarron DA, Morris CD, Young E, Roullet C, Drüeke T. Dietary calcium and blood pressure: modifying factors in specific populations. Am J Clin Nutr 1991; 54: 215-19. 
77. McCarron DA. Calcium metabolism in hipertension. Keio J Med 1995; 44 (4): 105-14.

78. Melton LJIII, O'Fallon WM, Riggs BL. Secular trends in the incidence of hip fratures. Calcif Tissue Int 1987; 41: 57-64.

79. Melton LJIII, Kan SH, Wahner HW et. al. Lifetime fracture risk: an approach to hip fracture risk assessment based on bone mineral density and age. $J$ Clin Epidemiol 1988; 41:985-94.

80. Meunier PJ, Chapuy MC, Arlot ME, Delmas PD, Duboeuf F. Can we stop loss and prevent hip fracture in the elderly? Osteoporos Int 1994; 1(Suppl): $71-6$.

81. Miller SA. Calcium and vitamin D deficiencies: a world issue? FAO: Food, Nutrition and Agriculture 1997; 20: 27-32.

82. Miwa $S$, Stoeltzner $W$. Über die bei jungen Hunden durch kälkarme Futterung enstehende Knochenerkrankung. Beitr Pathol Anat 1898; 24: 578 citado por Nordin BEC. Calcium in health and disease. FAO: Food, Nutrition and Agriculture 1997(a); 20: 13-26.

83. Mondini L, Monteiro CA. Mudanças no padrão de alimentação. In: Monteiro CA, organizador. Velhos e novos males da saúde no Brasil. A evolução do Pais e suas doenças. São Paulo: HUCITEC /NUPENS /USP; 1995. p. 7989.

84. Najas MS, Andreazza R, Souza ALM de, Sachs A, Guedes ACZ, Sampaio LR e col. Padrão alimentar de idosos de diferentes estratos socioeconômicos residentes em localidade urbana da região sudeste, Brasil. Rev Saúde públ 1994; 28: 187-91.

85. National Research Council (NRC). Recommended Dietary Allowances. Minerals - Calcium; 1989. p.174-83. 
86. National Institutes of Health (NIH). Consensus development panel on optimal calcium intake. JAMA 1994; 272: 1942-8.

87. Nguyen TV, Eisman JA, Kelly PJ, Sambrook PN. Risk factors for osteoporotic fractures in elderly men. Am J Epidemiol 1996; 144 (3): 25563.

88. Nguyen TV, Kelly PJ, Sambrook PN, Gilbert C, Pocock NA, Eisman JA. Lifestyle factors and bone density in the elderly: implications for osteoporosis prevention. J Bone Miner Res 1994; 9 (9): 1339-46.

89. Nilas L. Nutrition and fitness in the prophylaxis for age-related bone loss in women. In: Simopoulos AP. Nutrition and fitness in health and disease. World Rev Nutr Diet 1993; 72: 102-13.

90. Nordin BEC, Polley KJ. Metabolic consequences of the menopause. Calcif Tissue Int 1987; 41: 1-60.

91. Nordin BEC, Polley KJ, Need AG, Marshall D. The problem of calcium requeriment. Am J Clin Nutr 1987; 45: 1295-1304.

92. Nordin BEC, Morris HA. The calcium deficiency model for osteoporosis. Nut Rev 1989; 47(3): 65-72.

93. Nordin BEC, Heaney RP. Calcium supplementation of the diet: justified by present evidence. Br Med J 1990; 300: 1056-60.

94. Nordin BEC. Calcium in health and disease. FAO: Food, Nutrition and Agriculture 1997a; 20: 13-26.

95. Nordin BEC. The calcium controversy. Osteoporos Int 1997b; 7(Suppl.3): 17-23. 
96. Odell $W$, Heath $H$. Osteoporosis: pathophysiology, prevention, diagnosis and treatment. Disease-a-month 1993; XXXIX (11): 789 - 868.

97. O'Hanlon P, Kohes MB. Dietary studies of older Americans. Am J Clin Nutr 1978; 31: 1257-69.

98. Organização Mundial da Saúde (OMS). Comite de expertos en planificación y organización de los servicios geriátricos. Informe. Genebra, 1974. (Ser. Inf. Técn., 548).

99. Orwoll ES, Klein F. Osteoporosis in men. Endocr Rev 1995; 16: 87-116.

100. Ott SM. When bone mass fails to predict bone failure. Calcif. Tissue Int 1993; 53: 5139-42.

101. Park YK, Yetley EA, Calvo MS. Calcium intake levels in the United States: issues and considerations. FAO: Food, Nutrition and Agriculture 1997; 20 : $33-42$.

102. Patarra NL. Mudanças na dinâmica demográfica. In: Monteiro CA, organizador. Velhos e novos males da saúde no Brasil. A evolução do País e suas doenças. São Paulo: HUCITEC/NUPENS/USP; 1995. p. 6178.

103. Philippi ST, Szarfarc SC, Latterza AR. Virtual Nutri - sistema de análise nutricional [programa de computador]. Versão 1.0. São Paulo: Departamento de Nutrição, Faculdade de Saúde Pública, Universidade de São Paulo; 1996.

104. Pinheiro ABV, Lacerda EMA, Benzecry EH, Gomes MCS, Costa VM. Tabela para avaliação de consumo alimentar em medidas caseiras. Rio de Janeiro: Produção independente, 1996. 
105. Pommer G. Undersuchungen uber Osteomalacie und Rachitis. Leipzig, Germany, Vogel. 1885 citado por Nordin BEC. Calcium in health and disease. FAO: Food, Nutrition and Agriculture 1997(a); 20: 13-26.

106. Ray NF, Chan JK, Thamer M, Melton LJIII. Medical expenditures for the treatment of osteoporosis fractures in the United States in 1995: report from the National Osteoporosis Foundation. J Bone Miner Res 1995; 12 : 24-35.

107. Recker RR, Saville PD, Heaney RP. Effect of estrogens and calcium carbonate on bone loss in postmenopausal women. Ann Intern Med 1987; 87: 649-55.

108. Recker RR, Davies KM, Hinders SM, Heaney RP, Stegman MR, Kimmel DB. Bone gain in young adult women. JAMA 1992; 268: 2403-8.

109. Riggs BL, Wahner HW, Melton LJ, Richelson LS, Judd HL, O'Fallon M. Dietary calcium intake and rates of bones loss in women. $J$ Clin Invest 1987; 80: 979-82.

110. Rodríguez JA, Novik V. Ingesta de calcio y densidad ósea mineral en la menopausa. Datos de una muestra de mujeres chilenas seguidas durante cinco años con suplementación cálcica. Rev med Chile 1998; 126: 14550 .

111. Ryan AS, Craig LD, Finn SC. Nutrient intakes and dietary patterns of older americans: a national study. J Gerontol 1992; 47 (5): 145-50.

112. Sahyoun NR, Otradovec CL, Hartz SC, Jacob RA, Peters H, Russell RM, Mcgandy RB. Dietary intakes and biochemical indicators of nutritional status in na elderly, institutionalized population. Am J Clin Nutr 1988; 47: 524-533. 
113. Salamone LM, Glynn N, Black D, Epstein LP, Palermo L, Meilahn E et. al. Body composition and bone mineral density in premenopausal and early perimenopausak women. J Bone Miner Res 1995; 10 (11): 1762-68.

114. Sampaio LR. Avaliação da dieta de idosos residentes no município de São Paulo. São Paulo, 1997. [Dissertação de Mestrado - Faculdade de Ciências Farmacêuticas / Faculdade de Economia, Administração e Contabilidade / Faculdade de Saúde Pública -USP.]

115. Sandler RB, Slemenda CW, LaPorte RE, Culey JA, Schramm MM, Barresi ML, Kriska A. Postmenopausal bone density and milk consumption in childhood and adolescence. Am J Clin Nutr 1985; 42: 270-4.

116. Seeman E. The dilemma of osteoporosis in men. Am J Med 1995; 98 (suppl.2 A): 76-88.

117. Shoueri Junior R, Ramos LR, Papaléo Netto $M$. Crescimento populacional: aspectos demográficos e sociais. In: Carvalho Filho ET, Papaléo Netto M. Geriatria: fundamentos, clínica e terapêutica. São Paulo: Atheneu; 1994. p.9-29.

118. Shuman JM. Nutrição no envelhecimento. In: Mahan LK; Escott-Stump S. Krause: alimentos, nutrição e dietoterapia. São Paulo: Roca, 1998. p. 294315.

119. Silva LB, Monnerat MP. Alimentação para coletividades. Rio de Janeiro: Cultura Médica, 1986.

120. Sinake M, Wahner HW, Offord KP, Hodgson SF. Efficacy of nonloading exercises in prevention of vertebral bone loss in postmenopausal women: a controlled trial. Mayo Clin Proc 1989; 64: 762-9. 
121. Sloutskis D, Bernstein $M$, Burnand $B$, Morabia $A$. Consommation d'aliments riches en calcium dans la population adulte de suisse romande et du Tessin. Soz Praventivmed 1995; 40 (4): 201-8.

122. Spindler A, Lucero E, Berman A, Paz S, Uega E, Mautalen C. Bone mineral densitometry of a native populacion of Argentina with low calcium intake. J Rheumatol 1995; 22: 2148-51.

123. Steen B. Factors affecting the nutritional situation in the elderly outside and inside hospital. In: Prinsley DM, Sandstead HH. Nutrition and Aging. New York: ARL; 1990. p.345-354.

124. Stevens DA, Grivetti LE, McDonald RB. Nutrient intake of urban and rural elderly receiving home-delivered meals. J Am Diet Assoc 1992; 92 (6): $714-18$

125. Szejnfeld VL, Atra E, Baracat EC, Aldrighi JM, Civitelli R. Bone density in white Brazilian women: rapid loss at the time around the menopause. Calcif Tissue Int 1995; 56: 186-191.

126. Upritchard JE, Ball MJ. Fat and calcium intake in women dieters. Am J Clin Nutr 1996; 63 (1): 67-71.

127. Veras RP, Ramos LR, Kalache A. Crescimento da população idosa no Brasil: transformações e conseqüências na sociedade. Rev Saúde públ 1987; 21(3):225-33.

128. Vir SV, Love AHG. Dietary intake of institutionalised and noninstitutionalised aged. Irish Journal of Medical Science 1978; 147 (9): 301-7.

129. Wang MC, Villa ML, Marcus R, Kelsey JL. Associations of vitamin C, calcium and protein with bone mass in postmenopausal Mexican American women. Osteoporos Int 1997; 7: 533-8. 
130. Walker J, Ball M. Increasing calcium intake in women on a low-fat diet. Eur J Clin Nutr 1993; 47 (10): 718-23.

131. Weaver CM. Calcium bioavailability and its relation to osteoporosis. Proc Soc Exp Biol Med 1992; 200 (2): 157-60.

132. Wingate L. The epidemiology of osteoporosis. Journal of Medicine 1984; 15: $243-66$.

133. Witteman JCM. A prospective study of nutritional factors and hipertension among US women. Circulation 1989; 80:1320-7.

134. World Health Organizacion (WHO)- Grupo Cientifico sobre la Epidemiologia del Envejecimiento. Ginebra, 1983.

135. World Health Organization (WHO) Study Group- Diet, Nutrition and Prevention of Chronic Diseases. WHO Technical Report Series, 797, 1990.

136. World Health Organization. Study group on assessment of fracture risk and its application to screening for postmenopausal osteoporosis. Assessment of fracture risk and its application to screening for postmenopausal osteoporosis: report of a WHO study group. Geneva, 1994.

137. World Health Organization (WHO). Division of health promotion, education \& communication. Health of elderly. Background document. Genebra, 1995. (WHO/HPR/95.1).

139. Zerbini CAF. Osteoporose, uma revisão. Rev Bras Clin Terap 1998; 24 (1): 22-7. 


\section{ANEXOS}

Biblioteca/CIR

FACULDADE DE SAUUDE PÚBLICA

UNIVERSIDADE DE SAO PAULO 


\section{RELAÇÃO DE ANEXOS:}

Anexo 1: Aprovação da Comissão de Ética Médica do Hospital Heliópolis.

Anexo 2: Termo de consentimento informado do paciente.

Anexo 3: Instrumento de registro do consumo de alimentos.

Anexo 4: Orientações para o preenchimento do registro de consumo de alimentos.

Anexo 5: Tabela: Fontes alimentares de cálcio dietético, segundo quantidade do nutriente e tamanho da porção.

Anexo 6: Questionário retrospectivo de freqüência de consumo de leite e derivados lácteos fontes de cálcio.

Anexo 7: Protocolo de osteoporose. 


\section{Anexo 1:}

Aprovação da Comissão de Ética Médica do Hospital Heliópolis. 
SECRETARIA DE ESTADO DA SAÜDE

COMISSAO DE ETICA MEDICA

DO

HOSPITAL HELIOPOLIS

$\Delta$

Servigo de Rounetologle do Hoopltel Hellópolle

Doutor Ordetlane d. I. Zerblus

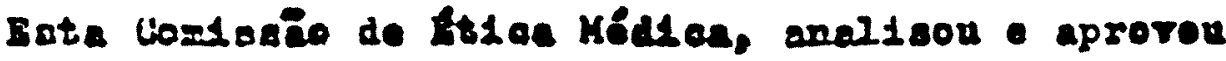

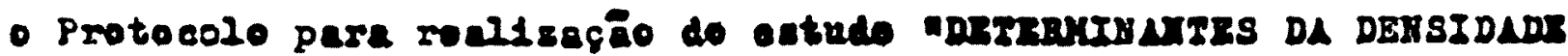

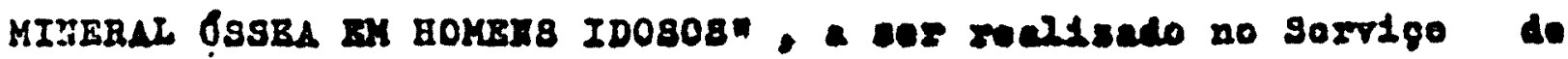

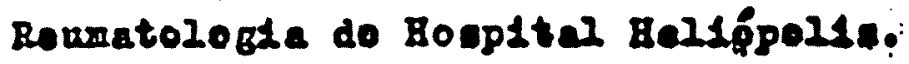

Lezbrasos que os peosentes dorosho perticlpar rom

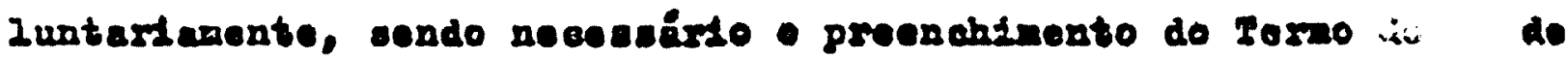
Ldesto, Indstrduelnonte:"

8on nats.

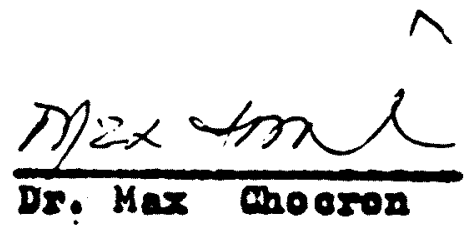

V10o-Prestdento

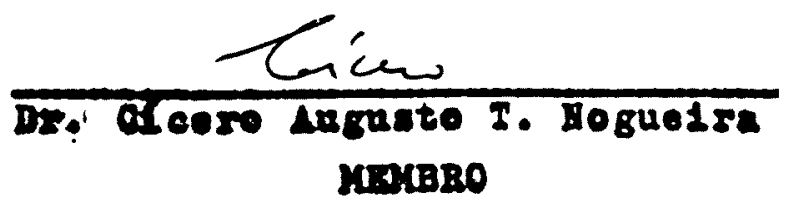

Matiaro
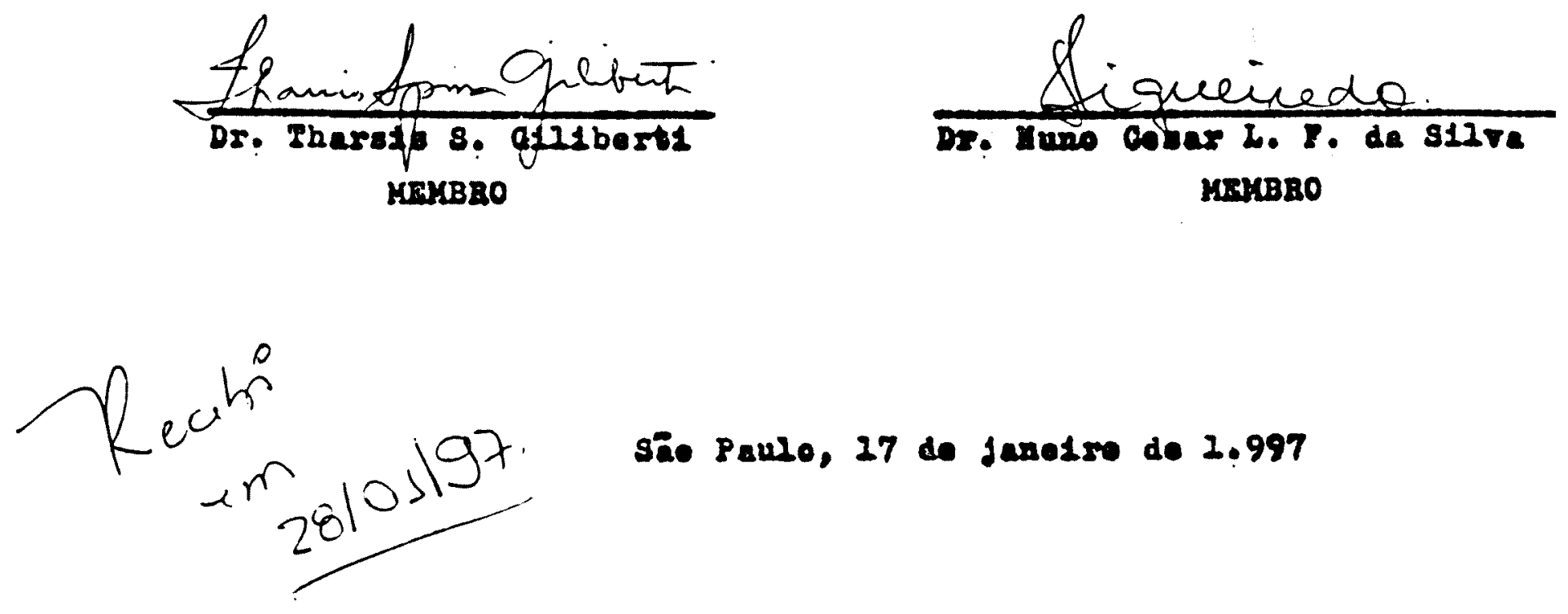

sâ. Palle, 27 de jurelse de 2,997 
Anexo 2:

Termo de consentimento informado do paciente. 
TERMO DE CONSENTIMENTO INFORMADO DO PACIENTE

INVESTIGADOR: DR. CRISTIANO A. F. ZERBINI

TÍtUlo: AVALIAÇÃo ClíNICA dOS FATORES DE RISCO PARA OSTEOPOROSE EM HOMENS

No PROTOCOLO: HH REUMA 001-97

$\mathrm{Eu}$,

serei um dos pacientes participantes deste estudo no PAM Heliópolis.

O objetivo deste estudo é reunir informações sobre a prevalência da osteoporose em homens no Brasil.

Eu compreendo que minha participação é inteiramente voluntária, não sendo de forma alguma prè-condição para que receba tratamento médico nesta instituição.

Fui informado que responderei a um questionário de saúde, serei examinado por uma equipe médica e farei densitometria óssea.

Fui informado que a densitometria óssea é um exame de rotina utilizado para avaliar a quantidade de massa óssea do esqueleto. Trata-se de exame simples, semelhante a um exame radiológico e não invasivo.

Fui informado que este é um estudo epidemiológico, isto é, um estudo para avaliar o estado de saúde da população. Este estudo não inclui a administração de remédios e também não inclui exames de laboratório. 
Fui informado que a equipe médica me informará dos resultados da densitometria óssea e, se necessário, poderei fazer tratamento médico para perda de massa óssea com esta mesma equipe no PAM Heliópolis.

Se eu tiver qualquer dúvida ou perguntas relativas ao estudo, no que diz respeito à minha participação, posso contactar o Dr. Cristiano Zerbini no telefone (011) 8524105 .

Eu concordo em seguir as instruçōes das pessoas conduzindo e monitorizando este estudo, de forma a obter o máximo de beneficios da atenção médica oferecida por esta pesquisa.

Nome do paciente:

Assinatura do paciente:

Data:

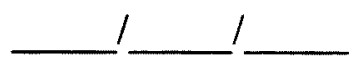

Endereço e telefone do paciente:

Nome da testemunha:

Data:

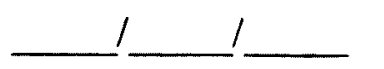

Assinatura do investigador:

Data: 


\section{Anexo 3:}

Instrumento de registro do consumo de alimentos 
No de registro:

REGISTRO DE CONSUMO DE ALIMENTOS

$1^{\circ}$ DIA

Data:

\begin{tabular}{|c|c|c|c|}
\hline Refeição & $\begin{array}{c}\text { Alimentos } \\
\text { (alimento, tipo e marca) }\end{array}$ & $\begin{array}{c}\text { Quantidade } \\
\text { (em medidas caseiras) }\end{array}$ & $\begin{array}{c}\text { Observações } \\
\text { (receitas, ingestão de água, } \\
\text { café e bebida alcoólica) }\end{array}$ \\
\hline $\begin{array}{l}\text { Café da manhã } \\
\text { Horário: }\end{array}$ & & & \\
\hline $\begin{array}{l}\text { Lanche da manh } \\
\text { Horário: }\end{array}$ & & & \\
\hline $\begin{array}{l}\text { Almoço } \\
\text { Horário: }\end{array}$ & & & \\
\hline $\begin{array}{l}\text { Lanche da tarde } \\
\text { Horário: }\end{array}$ & & & \\
\hline $\begin{array}{l}\text { Jantar } \\
\text { Horário: }\end{array}$ & & & \\
\hline $\begin{array}{l}\text { Lanche da noite } \\
\text { Horário: }\end{array}$ & & & \\
\hline
\end{tabular}


$N^{\circ}$ de registro:

REGISTRO DE CONSUMO DE ALIMENTOS

$2^{\circ}$ DIA

Data:

\begin{tabular}{|l|l|l|l|}
\hline \multicolumn{1}{|c|}{ Refeição } & $\begin{array}{c}\text { Alimentos } \\
\text { (alimento, tipo e marca) }\end{array}$ & $\begin{array}{c}\text { Quantidade } \\
\text { (em medidas caseiras) }\end{array}$ & $\begin{array}{c}\text { Observações } \\
\text { (receitas, ingestão de água, } \\
\text { café e bebida alcoólica) }\end{array}$ \\
\hline Café da manhã & & & \\
\hline Lorário: & & & \\
\hline Horário: & & & \\
\hline Horário: & & & \\
\hline Lancho da manhã & & & \\
\hline Horário: & & & \\
\hline Jantar & & & \\
\hline Horário: & & & \\
\hline Lanche da noite & & & \\
\hline
\end{tabular}


Data:

\begin{tabular}{|l|l|l|l|}
\hline \multicolumn{1}{|c|}{ Refeição } & $\begin{array}{c}\text { Alimentos } \\
\text { (alimento, tipo e marca) }\end{array}$ & $\begin{array}{c}\text { Quantidade } \\
\text { (em medidas caseiras) }\end{array}$ & $\begin{array}{c}\text { Observações } \\
\text { (receitas, ingestão de água, } \\
\text { café e bebida alcoólica) }\end{array}$ \\
\hline Café da manhã & & & \\
\hline Horário: & & & \\
\hline Horário: & & & \\
\hline Horário: & & & \\
\hline Lancho da manhã & & & \\
\hline Jantario: & & & \\
\hline Horário: & & & \\
\hline Lanche da noite & & & \\
\hline Horário: & & & \\
\hline
\end{tabular}




\section{Anexo 4:}

Orientações para o preenchimento do registro de consumo de alimentos. 


\section{Orientações para o preenchimento do registro de consumo de alimentos:}

1) Serão 3 dias de registro de consumo de alimentos. Para cada dia tem uma folha de registro.

2) Especificar todos os alimentos que foram ingeridos em cada dia.

3) Para cada alimento deverá ser colocada a quantidade ingerida.

4) Para anotar as quantidades usar medidas com as quais foram servidos os alimentos, como: colher de sopa (rasa, média ou cheia), colher de sobremesa, concha, escumadeira, xícara de chá, xícara de café, copo grande, copo americano (especificando se raso, médio ou cheio), unidade (pequena, média ou grande).

Exemplo: leite tipo $\mathrm{C}-1$ xícara de chá cheia queijo mussarela - 1 fatia média arroz - 1 escumadeira rasa

5) Anotar se, ao tomar café, suco ou chá foi usado açúcar ou adoçante.

6) Quando comer um "prato" mais sofisticado, incluir nas observações o recheio ou os ingredientes utilizados (receita).

Exemplo: -Pastel de frango com queijo

-Molho branco (leite tipo C, maisena e margarina)

7) Anotar o consumo de bebida alcoolica, água e café. 
Anexo 5:

Tabela: Fontes alimentares de cálcio dietético, segundo quantidade do nutriente e tamanho da porção. 
Tabela: Fontes alimentares de cálcio dietético, segundo quantidade do nutriente e tamanho da porção.

\begin{tabular}{|c|c|c|c|c|c|}
\hline Alimento & Grupo* & $\begin{array}{l}\text { Medida } \\
\text { caseira**}^{*}\end{array}$ & $\begin{array}{l}\text { Quanti- } \\
\text { dade } \\
\text { (g) }\end{array}$ & $\begin{array}{c}\text { mg cálcio / } \\
100 \mathrm{~g}\end{array}$ & $\begin{array}{c}\text { Mg cálcio / } \\
\text { porção } \\
( \pm 20 \%)\end{array}$ \\
\hline Leite semi-desnatado esterilizado & Leites & $1 \mathrm{Cp}$ cheio & 165 & 122 & $201(160-241)$ \\
\hline Leite de cabra & Leites & $1 \mathrm{Cp}$ cheio & 165 & 190 & $313(250-376)$ \\
\hline Leite de vaca "in natura" & Leites & $1 \mathrm{C} p$ cheio & 165 & 114 & $188(150-226)$ \\
\hline Leite em pó desnatado & Leites & 3 Col S rasa & 24 & 1231 & $295(236-354)$ \\
\hline Leite em pó integral & Leites & 3 Col S rasa & 24 & 912 & $219(175-263)$ \\
\hline Leite desnatado esterilizado & Leites & $1 \mathrm{Cp}$ cheio & 165 & 123 & $203(162-244)$ \\
\hline Leite integral esterilizado & Leites & $1 \mathrm{Cp}$ cheio & 165 & 119 & $196(157-235)$ \\
\hline Leite pasteurizado Tipo A & Leites & $1 \mathrm{Cp}$ cheio & 165 & 119 & $196(157-235)$ \\
\hline Leite pasteurizado Tipo B & Leites & $1 \mathrm{Cp}$ cheio & 165 & 119 & $196(157-235)$ \\
\hline Leite pasteurizado Tipo C & Leites & $1 \mathrm{CP}$ cheio & 165 & 119 & $196(157-235)$ \\
\hline Requeijão & Queijos & 1 Col S rasa & 15 & 565 & $85(68-102)$ \\
\hline Queijo brie & Queijos & 1 fatia média & 44 & 186 & $82(66-98)$ \\
\hline Queijo camembert & Queijos & 1 fatia média & 20 & 393 & $79(63-95)$ \\
\hline Queijo cheddar pasteurizado & Queijos & $1 \mathrm{Col}$ so & 15 & 729 & $113(90-136)$ \\
\hline Ricota & Queijos & 1 fatia média & 50 & 272 & $136(109-163)$ \\
\hline Queijo gouda & Queijos & 1 fatia média & 37 & 707 & $261(209-313)$ \\
\hline Queijo gruyére & Queijos & 1 fatia média & 50 & 1025 & $512(410-614)$ \\
\hline Queijo minas & Queijos & 1 fatia média & 30 & 685 & $205(164-246)$ \\
\hline Queijo mussarela & Queijos & 1 fatia média & 15 & 525 & $79(63-95)$ \\
\hline Queijo parmesão & Queijos & 1 Col S rasa & 9 & 1140 & $102(82-122)$ \\
\hline Queijo prato & Queijos & 1 fatia média & 20 & 840 & $168(134-202)$ \\
\hline Queijo provolone & Queijos & 1 fatia média & 35 & 764 & $267(214-320)$ \\
\hline Queijo roquefort & Queijos & 1 fatia média & 30 & 30 & $201(161-241)$ \\
\hline Queijo suiço & Queijos & 1 fatia média & 30 & 971 & $291(233-349)$ \\
\hline logurte desnatado frutas & logurtes & $1 \mathrm{C}$ & 200 & 152 & $304(243-365)$ \\
\hline logurte desnatado natural & logurtes & $1 \mathrm{C}$ & 200 & 182 & $364(291-437)$ \\
\hline logurte integral natural & logurtes & $1 \mathrm{C}$ & 200 & 120 & $240(192-288)$ \\
\hline Coalhada & logurtes & $1 \mathrm{C}$ & 200 & 440 & $880(704-1056)$ \\
\hline Sorvete de iogurte & Doces e Sob. ${ }^{1}$ & 1 bola média & 80 & 143 & $114(91-137)$ \\
\hline Sorvete caseiro com leite & Doces e Sob & 1 bola grande & 100 & 97 & $97(78-116)$ \\
\hline Sorvete industrializado com leite & Doces e Sob & 1 bola grande & 100 & 92 & $92(74-110)$ \\
\hline Chocolate ao leite & Doces e Sob & 1 tablete & 30 & 291 & $87(70-104)$ \\
\hline Doce de leite & Doces e Sob & 1 barra média & 40 & 176 & $70(56-84)$ \\
\hline Pudim de leite & Doces e Sob & 1 fatia média & 70 & 243 & $170(194-204)$ \\
\hline Brigadeiro & Doces e Sob & $1 \cup$ grande & 30 & 292 & $88(70-106)$ \\
\hline Flan com leite & Doces e Sob & $1 \mathrm{U}$ comercial & 120 & 113 & $136(109-163)$ \\
\hline Rapadura & Doces e Sob & 1 pedaço & 55 & 174 & $96(77-115)$ \\
\hline
\end{tabular}




\begin{tabular}{|c|c|c|c|c|c|}
\hline Agrião refogado & Hortaliças & 1E média & 75 & 121 & $91(73-109)$ \\
\hline Mostarda folha cozida & Hortaliças & $1 \mathrm{E}$ média & 90 & 220 & $198(158-238)$ \\
\hline Brócolis cozido & Hortaliças & $1 \mathrm{E}$ média & 70 & 114 & $80(64-96)$ \\
\hline Couve manteiga cozida & Hortaliças & $1 \mathrm{E}$ média & 94 & 72 & $68(54-82)$ \\
\hline Couve refogada & Hortaliças & 1 E média & 94 & 185 & $174(139-201)$ \\
\hline Espinafre cozido & Hortaliças & $1 \mathrm{E}$ média & 94 & 136 & $128(102-154)$ \\
\hline Caruru cozido & Hortaliças & $1 \mathrm{E}$ média & 94 & 96 & $90(72-108)$ \\
\hline Bertalha refogada & Hortaliças & 1 E média & 94 & 216 & $203(162-244)$ \\
\hline Sardinha enlatada s/pele e espinha & Peixe e F.M. ${ }^{2}$ & 1 filè & 34 & 402 & $137(109-164)$ \\
\hline Siri & Peixe e F.M. & $5 \cup p$ & 80 & 107 & $86(69-103)$ \\
\hline Manjuba frita com espinha & Peixe e F.M. & $7 \cup p$ & 74 & 279 & $207(166-248)$ \\
\hline Camarão cru & Peixe e F.M. & $3 \cup$ médias & 90 & 79 & $72(58-86)$ \\
\hline Camarăo seco & Peixe e F.M. & $2 \mathrm{Col} \mathrm{S}$ & 35 & 236 & $83(66-100)$ \\
\hline Ostra cozido & Peixe e F.M. & 1 porçäo & 100 & 75 & $75(60-90)$ \\
\hline Ostra crua fresca & Peixe e F.M. & 1 porção & 100 & 84 & $84(67-101)$ \\
\hline Bolo com leite & Prep. láct. ${ }^{3}$ & 1 fatia média & 70 & 127 & $89(71-107)$ \\
\hline Pão de queijo & Prep. Láct. & $1 \cup$ média & 50 & 174 & $87(69-104)$ \\
\hline Molho branco & Prep. Láct. & $1 \mathrm{Col}$ servir & 55 & 191 & $105(84-126)$ \\
\hline Bolinho de queijo & Prep. Láct. & $2 \cup p$ & 40 & 210 & $84(67-101)$ \\
\hline Pastel de queijo & Prep. Láct. & 1 U média & 70 & 357 & $250(200-300)$ \\
\hline Dobradinha & Outras prep. ${ }^{4}$ & $1 \mathrm{Co}$ & 100 & 96 & $96(77-115)$ \\
\hline Buchada & Outras prep. & $1 \mathrm{Co}$ & 100 & 92 & $92(74-110)$ \\
\hline Suflê de queijo & Prep. Láct. & 1 fatia média & 115 & 286 & $329(263-395)$ \\
\hline
\end{tabular}

FONTE: Franco, 1992; IBGE, 1977; Philippi e col., 1996; Pinheiro e col., 1996

* Onde: 1 - doces e sobr.= doces e sobremesas; 2 - peixes e F.M. = peixes e frutos do mar; 3 prep. láct.= preparações com produtos lácteos; 4 - outras preparações

** Onde: $C=$ copo; $p=$ pequeno; $C o l .=$ colher; $S=$ sopa; so = sobremesa; $U=$ unidade; $E=$ escumadeira; $\mathrm{Co}_{0}=$ concha. 
Anexo 6:

Questionário retrospectivo de freqüência de consumo de leite e derivados lácteos fontes de cálcio. 
$N^{\circ}$ de registro:

Questionário de freqüência de consumo de alimentos fontes de cálcio:

Para responder as perguntas abaixo, procure lembrar o que o(a) $\operatorname{sr}(a)$ fazia e como era sua vida quanto tinha entre 10 e 20 anos, 20 e 30 anos, e também 30 e 49 anos. Isto facilitará na lembrança de seus hábitos alimentares nesses períodos:

1) Quando o sr. tinha entre 10 e 20 anos, bebia leite:
( ) diariamente
( ) semanalmente
( ) nunca
( ) mensalmente
( )raramente
( ) não sabe

Quanto o sr. bebia de leite:

$\begin{array}{lll}\text { () não bebia } & (\text { ) meio copo } & (\text { ) um copo } \\ \text { ( ) dois copos } & (\text { ) não sabe }\end{array}$

2) Quando o sr. tinha entre 10 e 20 anos, bebia iogurte ou coalhada:
( ) diariamente
( ) semanalmente
( ) nunca
( ) mensalmente
( ) não sabe

Quanto o sr. bebia de iogurte ou coalhada:

$\begin{array}{lll}\text { () não bebia ( ) meio copo } & \text { ( ) um copo } \\ \text { ( ) dois copos } & \text { ( ) não sabe } & \text { ( ) outro }\end{array}$

3) Quando o sr. tinha entre 10 e 20 anos, comia queijo:
( ) diariamente
( ) semanalmente
( ) mensalmente
( ) raramente
( ) nunca
( ) não sabe

Quanto o sr. comia de queijo:
( ) não comia
( ) uma fatia
( ) duas fatias
( ) não sabe
( ) outro

4) Quando o sr. tinha entre 20 e 30 anos, bebia leite:
( ) diariamente
( ) semanalmente
( ) mensalmente
( ) raramente
( ) nunca
( ) não sabe

Quanto o sr. bebia de leite:

$\begin{array}{lll}\text { ( ) não bebia } & (\text { ) meio copo } & \text { ( ) um copo } \\ \text { () dois copos } & \text { ( ) não sabe } & \text { ( ) outro }\end{array}$

5) Quando o sr. tinha entre 20 e 30 anos, bebia iogurte ou coalhada:
( ) diariamente
( ) semanalmente
) raramente
( ) nunca
( ) mensalmente
( ) não sabe 
Quanto o sr. bebia de iogurte ou coalhada:

( ) não bebia

( ) dois copos

( ) meio copo

( )um copo

( ) não sabe ( ) outro

6) Quando o sr. tinha entre 20 e 30 anos, comia queijo:
( ) diariamente
( ) semanalmente
( ) mensalmente
( ) raramente
( ) nunca
( ) não sabe

Quanto o sr. comia de queijo:

( ) não comia ( ) uma fatia ( ) duas fatias

( ) não sabe ( ) outro

7) Quando o sr tinha entre 30 e 49 anos, bebia leite:

$\begin{array}{lll}\text { () diariamente } & \text { ( ) semanalmente } & \text { ( ) mensalmente } \\ \text { ( ) raramente } & \text { ( ) nunca } & \text { ( ) não sabe }\end{array}$

Quanto o sr. bebia de leite:

( ) não bebia ( ) meio copo ( )um copo

( ) dois copos ( ) não sabe ( ) outro

8) Quando o sr. tinha entre 30 e 49 anos, bebia iogurte ou coalhada:
( ) diariamente
( ) semanalmente
( ) raramente
( ) nunca
( ) mensalmente
( ) não sabe

Quanto o sr. bebia de iogurte ou coalhada:
( ) não bebia
( ) meio copo
Jum copo
( ) dois copos
( ) não sabe
) outro

9) Quando o sr. tinha entre 30 e 49 anos, comia queijo:
( ) diariamente
( ) semanalmente
( ) nunca
( ) mensalmente
( ) não sabe

Quanto o sr. comia de queijo:
( ) não comia
( ) uma fatia
( ) duas fatias

( ) não sabe

( ) outro

Agradecemos pela sua colaboração reforçando nosso interesse em contribuir, com esse trabalho, com a promoção da saúde e da qualidade de vida das pessoas. 
Anexo 7:

Protocolo de osteoporose. 
- $\mathrm{N}^{\circ}$ de registro:

Data:

- Nome:

- RG - PAM:

Endereço:

Telefone:

CEP:

Sexo: $\square \mathrm{M}(1) \quad \square \mathrm{F}(2)$

Raça: $\square$ B(1) $\square \operatorname{Pt}(2) \quad \square \operatorname{Pd(3)~} \square$ Am(4) $\square$ Outros(5)

Data de Nascimento:

Naturalidade:

Código:

Estado civil: $\quad \square$ solteiro(1) $\quad \square$ casado(2) $\square$ separado(3) $\quad \square$ viúvo(4)

Profissão: Código:

se aposentado:

a) motivo da aposentadoria: $\square$ tempo de serviço(1) $\square$ invalidez(2) $\quad \square$ idade(3) $\square$ especial(4)

b) há quanto tempo: anos

c) atividade anterior:

Código:

Escolaridade:

$\square$ analfabeto(1) $\square$ sabe ler e escrever(2) $\square 1^{\circ}$ grau incompleto(3)

$1^{\circ}$ grau completo(4)

$2^{\circ}$ grau incompleto(5) $\quad \square 2^{\circ}$ grau completo(6) $\square$ superior(7) 
- Antecedentes mórbidos

- endócrinos:

hipotireoidismo:

$\operatorname{sim}(1) \quad \square$ não(2) $\square$ não sabe(9)

hipertireoidismo:

$\square \operatorname{sim}(1) \quad \square$ não(2) $\square$ não sabe(9)

hiperparatireoidismo:

$\square \operatorname{sim}(1) \quad \square$ não(2) $\square$ não sabe(9)

diabetes mellitus:

$\operatorname{sim}(1) \square$ não(2) $\square$ não sabe(9)

- gastrointestinal:

doença hepática:

$\square \operatorname{sim}(1) \quad \square$ não(2) $\square$ não sabe(9)

gastrectomia:

$\square \operatorname{sim}(1) \quad \square$ não(2) $\square$ não sabe(9)

colite:

$\square \operatorname{sim}(1) \quad \square$ não(2) $\square$ não sabe(9)

outras (qual):

- calculose renal:

$\square \operatorname{sim}(1) \quad \square$ não(2) $\square$ não sabe(9)

- mieloma múltiplo:

$\square \operatorname{sim}(1) \quad \square$ não(2) $\square$ não sabe(9)

- outras neoplasias (qual):

- Medicamentos:

- corticosteróides:

- anticonvulsivantes:

- anti-ácidos:

- diuréticos tiazídicos:

- diuréticos não tiazídicos:

- suplemento de cálcio:

\begin{tabular}{|c|c|c|c|}
\hline $\begin{array}{l}\square \operatorname{sim}(1) \\
\text { dose: }\end{array}$ & não(2) & $\begin{array}{l}\square \text { algum dia usou(3) } \\
\text { tempo de uso: }\end{array}$ & não sabe(9) \\
\hline $\begin{array}{l}\square \operatorname{sim}(1) \\
\text { dose: }\end{array}$ & não(2) & $\begin{array}{l}\square \text { algum dia usou(3) } \\
\text { tempo de uso: }\end{array}$ & não sabe(9) \\
\hline $\begin{array}{l}\square \operatorname{sim}(1) \\
\text { dose: }\end{array}$ & não(2) & $\begin{array}{l}\square \text { algum dia usou(3) } \\
\text { tempo de uso: }\end{array}$ & não sabe(9) \\
\hline $\begin{array}{l}\square \operatorname{sim}(1) \\
\text { dose: }\end{array}$ & não(2) & $\begin{array}{l}\square \text { algum dia usou( } 3 \text { ) } \\
\text { tempo de uso: }\end{array}$ & não sabe(9) \\
\hline $\begin{array}{l}\square \operatorname{sim}(1) \\
\text { dose: }\end{array}$ & não(2) & $\begin{array}{l}\square \text { algum dia usou(3) } \\
\text { tempo de uso: }\end{array}$ & não sabe(9) \\
\hline $\begin{array}{l}\square \operatorname{sim}(1) \\
\text { dose: }\end{array}$ & não(2) & $\begin{array}{l}\square \text { algum dia usou( } 3 \text { ) } \\
\text { tempo de uso: }\end{array}$ & não sabe(9) \\
\hline
\end{tabular}


- Já teve fratura: idade: (anos) quantas vezes?

$\square$ não traumática(1) $\square$ traumática(2) $\square$ não(3) $\square$ não sabe(9)

$\square$ radio(1) $\square$ vértebra(2) $\square$ fềmur(3) outro: Código:

- Mãe com fratura após 50 anos:

$\square$ não traumática(1) $\square$ traumática(2) $\square$ não(3) $\square$ não sabe(9)

$\square$ radio(1) $\square$ vértebra(2) $\square$ fềmur(3) outro Código:

- Pai com fratura após 50 anos:

$\square$ não traumática(1) $\square$ traumática(2) $\square$ não(3) $\square$ não sabe(9)

$\square$ radio(1) $\square$ vértebra(2) $\square$ fềmur(3) outro: Código:

- Fuma atualmente? $\square \operatorname{sim}(1) \quad \square$ não(2) se sim: quantos cigarros por dia: há quanto tempo:

tipo de fumo: $\square$ cigarro sem filtro(1) $\square$ cigarro com filtro(2) $\square$ cachimbo(3) $\square$ charuto(4) $\square$ outro(5)

Parou de fumar? $\square \operatorname{sim}(1) \square$ não(2) há quanto tempo?

fumou por quanto tempo? fumava quantos cigarros por dia?

- Consumo de bebida:

\begin{tabular}{|l|l|l|l|}
\hline \multicolumn{1}{|c|}{ tipo de bebida } & $\begin{array}{c}\text { periodicidade } \\
\text { (diária, semanal, etc) }\end{array}$ & $\begin{array}{c}\text { quantidade } \\
\text { (copos ou xicara) }\end{array}$ & \\
\hline aguardente & & & \\
\hline cerveja & & & \\
\hline conhaque & & & \\
\hline licor & & & \\
\hline vinho & & & \\
\hline whisky & & & \\
\hline café & & & \\
\hline refrigerantes cola & & & \\
\hline & & & \\
\hline & & & \\
\hline
\end{tabular}

